LAWRENCE LIVERMORE NATIONAL LABORATORY

\section{Nitrate Contamination in California Groundwater: An Integrated Approach to Basin Assessment and Resource Protection}

\section{LLNL Nitrate Working Group}

Bradley K Esser, G. Bryant Hudson, and Jean E Moran Chemistry \& Material Science Directorate Harry Beller, Tina Carlsen, Brendan Dooher, Paula Krauter, Walt Mcnab, Vic Madrid, Dave Rice, and Matthew Verce Environmental Protection Department

Nina Rosenberg Earth and Energy Directorate

An LLNL Water Initiative White Paper Lawrence Livermore National Laboratory 10 December 2002 


\section{Disclaimer}

This document was prepared as an account of work sponsored by an agency of the United States government. Neither the United States government nor Lawrence Livermore National Security, LLC, nor any of their employees makes any warranty, expressed or implied, or assumes any legal liability or responsibility for the accuracy, completeness, or usefulness of any information, apparatus, product, or process disclosed, or represents that its use would not infringe privately owned rights. Reference herein to any specific commercial product, process, or service by trade name, trademark, manufacturer, or otherwise does not necessarily constitute or imply its endorsement, recommendation, or favoring by the United States government or Lawrence Livermore National Security, LLC. The views and opinions of authors expressed herein do not necessarily state or reflect those of the United States government or Lawrence Livermore National Security, LLC, and shall not be used for advertising or product endorsement purposes.

\section{Auspices Statement}

Work performed under the auspices of the U.S. Department of Energy by the Lawrence Livermore National Laboratory under Contract W-7405-ENG-48. 


\section{Nitrate Contamination in California Groundwater: An Integrated Approach to Basin Assessment and Resource Protection}

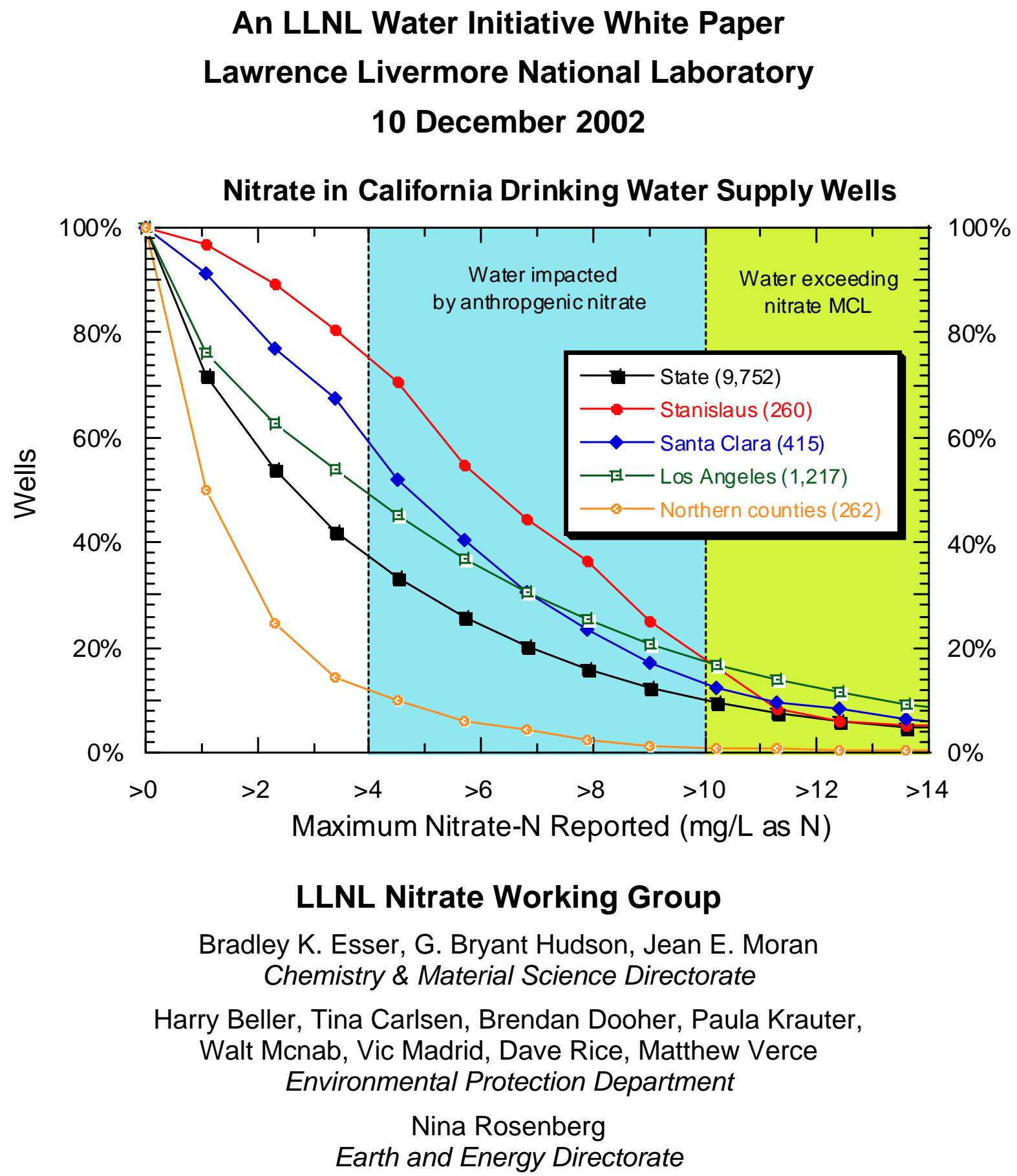




\section{Suggested citation:}

Esser, B. K., Hudson, G. B., Moran, J. E., Beller, H., Carlsen, T., Dooher, B., Paula Krauter, Mcnab, W., Madrid, V., Rice, D., Verce, M., and Rosenberg, N. (2002) Nitrate Contamination in California Groundwater: An Integrated Approach to Basin Assessment and Resource Protection. Lawrence Livermore National Laboratory LLNL-TR-466420, $62 \mathrm{pp}$. 


\section{Executive Summary}

\section{BACKGROUND}

Nitrate contamination of California drinking water supplies is pervasive- about $10 \%$ of California public drinking water supply wells produce water that exceeds the regulatory drinking water limit, and a much larger fraction produce water which approaches the limit. As the population of California increases by 50\% over the next 20 years, water resources will be in critically short supply. If the State can develop acceptable methods to prevent nitrate contamination of susceptible groundwaters and to remediate contaminated groundwaters, then the volume of available "new" water will be a critical benefit to California's continuing growth and prosperity.

Nitrate is commonly viewed as an intractable problem for three reasons.

- First, nitrate contamination is ubiquitous in both surface and groundwater - a substantial number of California public and especially private groundwater wells have nitrate levels that exceed or approach regulatory limits for drinking water, and a significant fraction of surface water supplies have nitrate concentrations that would preclude their use for groundwater recharge if draft DHS regulations were adopted.

- Second, the activities that contribute anthropogenic nitrate to groundwater - animal operations, crop fertilization, wastewater treatment discharge, septic systems - are ongoing and essential to the industry and commerce of the State of California.

- Finally, nitrate is expensive to remove from drinking water supplies, especially in public and private systems that rely on untreated groundwater and do not have the necessary water treatment infrastructure.

These factors combine to make nitrate the number-one contaminant threat to California's drinking water supply and at the same time may represent an opportunity to make important strides in providing sufficient water to meet California's future growth. A working group at LLNL has surveyed the current approach to characterizing and managing groundwater nitrate contamination in California, and has identified specific opportunities for developing better characterization methods.

\section{SPECIFIC RECOMMENDATIONS FOR GROUNDWATER NITRATE MANAGEMENT}

\section{Conduct a Groundwater Basin Assessment of Nitrate Inventories and Impacts}

The ultimate goal of the Groundwater Quality Monitoring Act of 2001 (AB599) is the implementation of a comprehensive monitoring program to allow groundwater basin assessment. Assessment is a broad term still being defined by the AB599 Interagency Task Force and Advisory Board, but encompasses assessing susceptibility of groundwater to contamination, characterizing current water quality in a basin, and predicting future water quality under different conditions. To meet these goals, basin assessment must consider the current inventory of nitrate in basin soils and waters, current and past source loading, groundwater recharge and transport, 
and nitrogen cycling in the soil, vadose and saturated zone. Nitrate occurs naturally, has relatively low-intensity point, distributed and nonpoint sources, and has a long history of introduction into the environment. Surface nitrogen loading has dramatically increased in the last 50 years, making groundwater ages a useful first approach to vulnerability assessment. Supplementing CAS data with nitrate source loading and aquifer property data would be an even more powerful approach to assessing the susceptibility of groundwater basins to pervasive nitrate contamination. True characterization of volume of groundwater impacted by nitrate contamination in the State, and development of a predictive reactive transport model for nitrate will require three-dimensional characterization and modeling at the basin scale. Once fully developed, such models could aid decision makers in water resource management, in comprehensive monitoring, and in nitrate management planning. Specific tasks would include:

- Demonstrate the utility of the existing CAS database to characterize nitrate contamination and assess groundwater basin susceptibility

- Import nitrate source data, soil data, and hydrogeologic basin data into the GEIMS database; and build nitrate data visualization and analysis tools for the Geotracker GIS

- Assess the susceptibility of groundwater basins and individual wells to nitrate contamination at a scale useful to basin management planning

- Characterize the distribution of anthropogenic and natural nitrate in groundwater basins and develop a comprehensive monitoring plan using existing data, simple hydrogeologic models and data visualization

- Model the future distribution of nitrate in a groundwater basin and at an individual well under current conditions and under different management plans

\section{Characterize and Quantify Aquifer Denitrification Assimilative Capacity}

Development of better characterization methods would lead a better understanding of aquifer assimilative capacity and of the associated human health risks of pervasive nitrate contamination. Understanding and quantifying denitrification in the saturated and recharge zone is important to accurately assessing groundwater basin response to nitrate loading, to designing in situ approaches to remediation (i.e. monitored natural attenuation or enhanced biodenitrification), and to developing nutrient discharge limits for agriculture. Denitrification is a microbiallymediated process that converts nitrate into nitrogen, a harmless gas that constitutes $80 \%$ of the atmosphere. Denitrification during recharge and in the saturated zone can mitigate nitrate contamination and thereby reduce risk associated with drinking water supplies.

Denitrification has been long recognized as an important process in the soil zone, in manure and fertilizer management, in wastewater treatment, and in both in situ and ex situ treatment of nitrate-contaminated groundwater. Although the existence of denitrification in the saturated zone and deep vadose zone has long been known, its quantitative impact on the nitrate budget of shallow groundwaters is only now being carefully assessed. Subsurface denitrification can have a powerful mitigating effect on nitrate loading, but the effect is likely to be basin- and sourcedependent. The terms "basin denitrifying capacity" or "aquifer assimilative capacity" capture this concept.

- Survey denitrification in a subset of GAMA wells where aquifer vulnerability has already been assessed.

Page 6 of 62 
- Characterize and quantify denitrification during recharge and transport in individual basins using newly developed analytical techniques

- Develop appropriate proxies for aquifer assimilative capacity in basin assessment

- Develop a saturated zone denitrification model for nitrate management planning and groundwater basin assessment

\section{Improve Nitrate Source Attribution and Assess the Occurrence of Nitrate Co-contaminants}

Knowing the source of nitrate in a contaminated aquifer is critical for managing surface operations to prevent future contamination, and for evaluating exposure of human populations to nitrate co-contaminants. Source attribution can be addressed, at least in part, by monitoring the stable isotopic composition of the nitrogen and oxygen in nitrate dissolved in groundwater. In addition, detection in groundwater of nitrate co-contaminants that are specific to certain land uses (such as herbicides used in agriculture, xenobiotics from septic tanks, or pathogens associated with confined animal operations) can also be valuable for source attribution. In addition to their relevance to source attribution, co-contaminants may pose human health risks beyond those posed by nitrate itself. The pervasiveness of nitrate-impacted waters in the State's drinking water supply increases the probability of low-level human exposure to contaminants that have the same source as anthropogenic nitrate (primarily agricultural operations, animal operations, or septic systems). Understanding the occurrence of these contaminants has implications for human health risk assessment (especially where synergistic effects are important) and for remediation (i.e., which treatment methods would be appropriate to address all contaminants). Since the occurrence of nitrate co-contaminants has not been adequately addressed to date, we propose measurement of potentially significant co-contaminants and assessment of their value for source attribution and human health risk evaluation.

- Evaluate the usefulness of nitrate co-contaminants for source attribution, susceptibility assessment, assessment of management practices, and remediation planning

- Develop and use new analytical techniques for identifying prevalent herbicides and their transformation products in nitrate-contaminated California groundwater

- Develop and use new analytical techniques for bacterial and viral co-contaminants in nitrate-contaminated California groundwater

- Develop and use new analytical techniques for human waste co-contaminants in nitratecontaminated California groundwater

\section{Assess the Effect on Nitrate Management Plans and Best Management Practices on Groundwater}

The State Water Resources Quality Control Board is responsible for protecting California's groundwater resources from degradation. Remediation of waters that exceed the MCL for nitrate is expensive. A far more cost-effective approach is to manage source loading to prevent 
groundwater nitrate levels from exceeding drinking water standards, with priority given to those basins that have elevated levels of nitrate and are currently receiving significant fixed nitrogen input. California, to a large extent, has adopted a non-regulatory approach with heavy reliance on developing and encouraging adoption of best management practices for fertilization and animal operations. Demonstrating the effectiveness of specific nutrient management practices and plans is important in gaining acceptance of these approaches. Quantifying the effect of nitrate management practices on groundwater nitrate, however, is difficult and can rarely be accomplished by simple time-series concentration data, especially over short time scales in deep drinking-water supply aquifers. Long-term assessment of land use and nitrate management practices on deep basins is a key gap in the current approach to nitrate management.

The decision to remediate nitrate-contaminated groundwater must be made with full knowledge of technical feasibility, total cost, and the status of new remediation technologies. If new supplies of uncontaminated water (e.g. from drilling new wells) are available and if contamination of those supplies can be prevented or mitigated through effective management, waiting for the development of new inexpensive technologies to remove nitrate may be feasible.

- Use CAS groundwater ages to demonstrate the relationship between land use and groundwater nitrate concentrations

- Perform focused field studies to demonstrate the utility of an integrated approach to groundwater nitrate characterization in nitrate assessment and management. Such studies could include:

o Nitrate plume characterization (source, history, future)

o Evaluation of temporal changes in nitrate along groundwater flow paths

o Agricultural management field studies

o Artificial recharge field studies

- Critically review available and emerging nitrate remediation technologies and assess their cost, applicability and limitations in the context of California water and energy. 


\section{Background: The Nitrate Problem in California Groundwater}

Nitrate contamination of California drinking water supplies is a pervasive and very serious problem. Nitrate is regulated as a primary contaminant by both federal and state agencies, and can have significant human health effects. Nitrate contamination is ubiquitous in both surface and groundwater - a significant number of California public and especially private groundwater wells have nitrate levels that exceed or approach regulatory limits for drinking water, and a significant fraction of surface water supplies have nitrate concentrations that would preclude their use for groundwater recharge if draft DHS regulations were adopted. The anthropogenic activities that contribute nitrate to groundwater - animal operations, crop fertilization, wastewater treatment discharge, septic systems - are ongoing and essential to the industry and commerce of the State of California. Best management practices can mitigate source loading but not eliminate it. And finally, nitrate is expensive to remove from drinking water supplies, especially in public and private systems that rely on untreated groundwater and do not have the necessary water treatment infrastructure. These factors combine to make nitrate the number-one contaminant threat to California's drinking water supply.

\section{The current regulatory framework}

In 1977, the State of California adopted a MCL of $45 \mathrm{mg} / \mathrm{L}$ for nitrate in public drinking water, essentially equivalent to the federal MCL of $10 \mathrm{mg} / \mathrm{L}$ nitrate-nitrogen (nitrate-N) adopted by the U.S. EPA under authority of the 1974 Safe Drinking Water Act. In 1991, the U.S. EPA set additional MCLs for nitrite-N (1 mg/L) and for total nitrate and nitrite N (10 mg/L) (U.S. EPA, 1991). In 1997, under authority of the California Safe Drinking Water Act of 1996, the State of California set PHGs for nitrate, nitrite, and joint nitrate/nitrite in drinking water that corresponded to the federal MCLs (California EPA, 1997). More recently (August 2002), the California Department of Health Services has proposed a set of regulations on the recharge of groundwater with recycled water. For nitrogen, the draft regulation requires that the total $\mathrm{N}$ of recycled or blended water used for recharge shall not exceed $3 \mathrm{mg} / \mathrm{L}$ unless the project sponsor demonstrates that the nitrite and nitrate drinking water standards are consistently met in the recharge water (California DHS, 2002).

Nitrate concentrations in water are reported in different units in the regulatory literature: as milligrams of nitrate per liter of water, or as milligrams of nitrate-N per liter of water. California is the only state that has set an MCL for nitrate in units of nitrate rather than nitrate-N. California's regulations for nitrite, for nitrite plus nitrate, and for total $\mathrm{N}$ are set in units of $\mathrm{N}$, as are all Federal regulations. In addition, much of the academic literature reports nitrate as nitrate$\mathrm{N}$. In this report, we use the nitrate-N convention.

The current standards for nitrate and nitrite in drinking water are based on protection from infant methemoglobinemia (blue baby syndrome) (Fan and Steinberg, 1996). Consensus exists among regulatory agencies and most researchers that the present standards are adequate. Reviews by the U.S. EPA (1990a), the NRC (1995), and the California EPA (California EPA, 1997; Fan and Steinberg, 1996; Fan et al., 1987) have concluded that these standards protect the very young from nitrate-induced toxicity. The issue of whether these standards are too low, especially in light of questions about the role of bacterial contamination in methemoglobinemia, has been raised (e.g. Avery, 2001). However, from a regulatory viewpoint the low margin of safety 
between no-observed-adverse effect levels (10 mg/L nitrate-N) and lowest-observable-effect levels (11-20 mg/L nitrate-N), the potential severity of the effect (death), and the uncertainties in the data argue for a conservative approach (Fan and Steinberg, 1996). Furthermore, recent epidemiologic studies have provided tentative evidence of a link between increased incidence of cancer and spontaneous abortions with the presence of nitrate in drinking water supplies at levels near the present standard (Ward et al., 1996; Weyer et al., 2001). Although research into the human health effects of nitrate and nitrite continues, we know of no serious effort to change the present regulation.

\section{Groundwater nitrate contamination}

Nitrate is a ubiquitous contaminant in U.S. and California surface and groundwaters. Nitrate occurs naturally in groundwaters at levels generally less than $2 \mathrm{mg} / \mathrm{L}$ (Mueller and Helsel, 1996), and nitrite is generally negligible. Exposure to high levels is almost always associated with contaminated water supplies. The U.S. EPA (1990b) has estimated that about 1.7 million people (including 270,000 infants) or $8 \%$ of population are exposed to water with nitrate concentrations in excess of the regulatory limits for drinking water. Of domestic wells sampled by the USGS National Water-Quality Assessment (NAWQA), 9\% had nitrate concentrations exceeding the regulatory limit, as compared to $2-3 \%$ of public supply wells nationwide (Nolan et al., 2002). The NAWQA study has also demonstrated that a large fraction of the nation's groundwater supply is impacted by anthropogenic nitrate contamination, where impact is defined as the presence of nitrate above a threshold value of 3-4 mg/L nitrate-N (Nolan et al., 2002; Nolan et al., 1997; Squillace et al., 2002).

The State of California has long recognized the nitrate problem. In 1988, the SWRCB produced a report to the legislature that characterized nitrate contamination in the state geographically, identified sources of data for nitrate in drinking water, and developed work plans to address the problem (Anton et al., 1988). To illustrate the problem, Anton et al. (1988) reported that the Metropolitan Water District of southern California was losing up to $4 \%$ of its drinking water supply to nitrate, as compared to less than $0.5 \%$ to toxic organic contamination, and that almost half of the groundwater contained in unconfined aquifers in Salinas Valley exceeded the drinking water MCL. The report drew on a wide variety of sources to characterize nitrate contamination in state drinking water supplies, including requests for input to state and federal agencies, the U.S. EPA STORET database, loan applications to DHS, and published and unpublished technical literature. The geographic distribution of nitrate contamination in groundwater as delineated in the report is shown in Figure 1. 

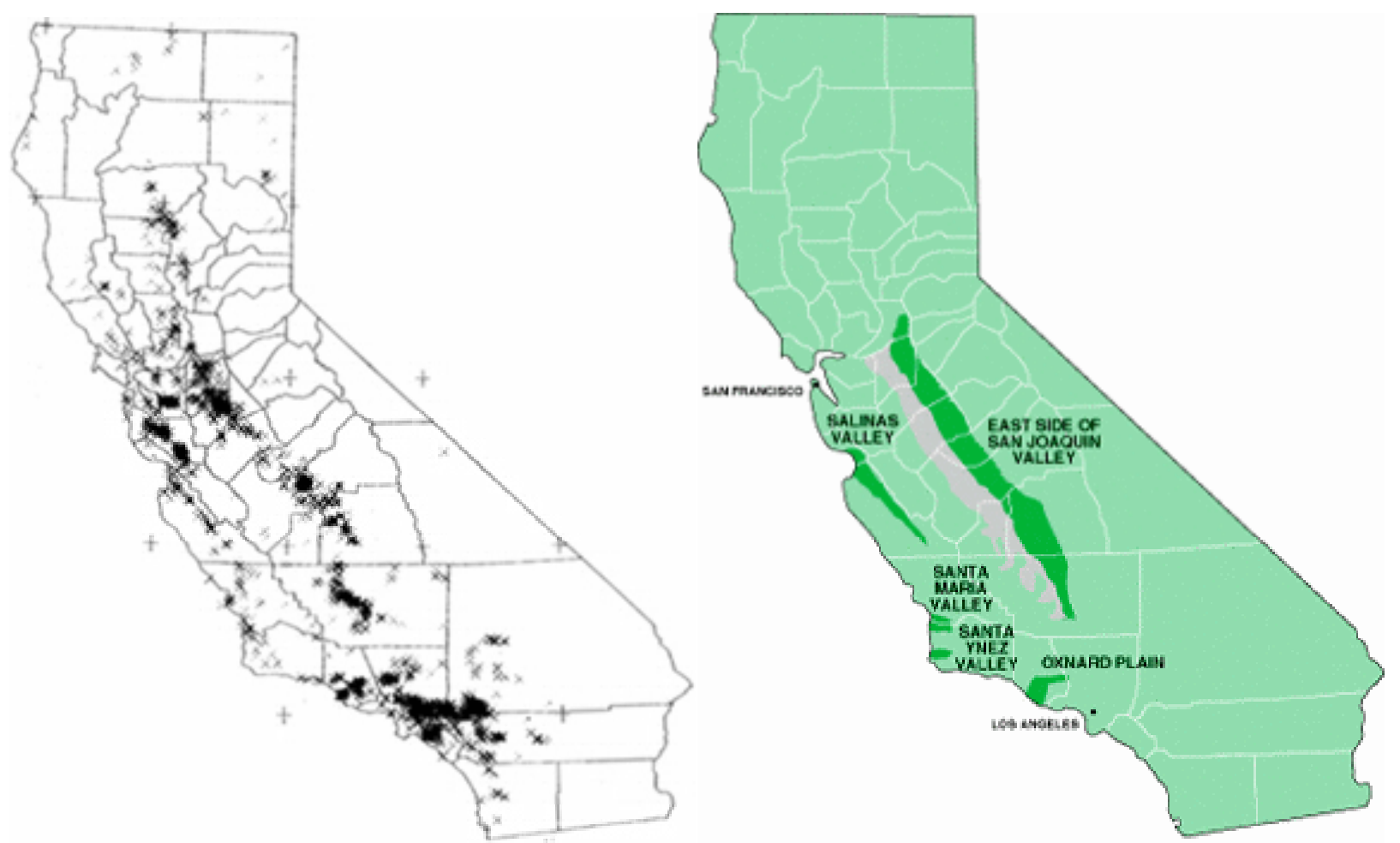

Figure 1. Maps of groundwater nitrate impact and susceptibility in California. The map on the left plots wells where nitrate- $\mathrm{N}$ levels occurred in the range 4.5-10 mg/L between 1975 through 1987 (Anton et al., 1988). The map on the left is the CDFA map of groundwater basins sensitive to nitrate contamination (http://www.cdfa.ca.gov/is/Frep/about_frep.htm).

The current DHS water quality database for public drinking water supply wells accessed through Geotracker confirms the conclusion of the 1988 SWRCB report that nitrate is a quantitative threat the state drinking water supply. In 1988, approximately $10 \%$ of the California groundwater analyses in the U.S. EPA STORET database exceeded the drinking water MCL. In August 2002 slightly over 9\% of the wells in the Geotracker database had maximum nitrate concentrations that exceeded the drinking water MCL (Figure 2). In 1988, SWRCB reported that Stanislaus County led the State in the number of loan applications from small systems for solution of nitrate problems (Anton et al., 1988). Today, approximately $80 \%$ of the groundwater wells in the Stanislaus County DHS database are impacted by nitrate contamination (i.e., have maximum concentrations greater than $3 \mathrm{mg} / \mathrm{L}$ ), and greater than $15 \%$ have maximum concentrations that exceed the drinking water limit. In 1988, the Metropolitan Water District reported that $12 \%$ of the wells in its service area exceeded the drinking water limit. In the Geotracker DHS database, greater than $16 \%$ of the wells in Los Angeles County have maximum nitrate concentrations that exceed the drinking water limit. In contrast, groundwaters in northern counties (Shasta, Mendocino, Trinity) are not impacted by nitrate contamination (Figures 1 and 2), and have a median nitrate concentration of $1 \mathrm{mg} / \mathrm{L}$, which is consistent with an average natural groundwater nitrate concentration of $2 \mathrm{mg} / \mathrm{L}$ (Mueller and Helsel, 1996). What is remarkable about the distribution of nitrate in California groundwater drinking water supplies is the large fraction of supply that is impacted by anthropogenic nitrate but that does not exceed the Federal drinking water standards. One-third of wells in the State, one half of wells in Santa Clara 
County, and two thirds of wells in Stanislaus County have reported maximum nitrate levels of between 4 and $10 \mathrm{mg} / \mathrm{L}$, a relatively narrow range. Managing these basins to prevent loss of water supply by nitrate contamination should be a number-one priority for the State Board.

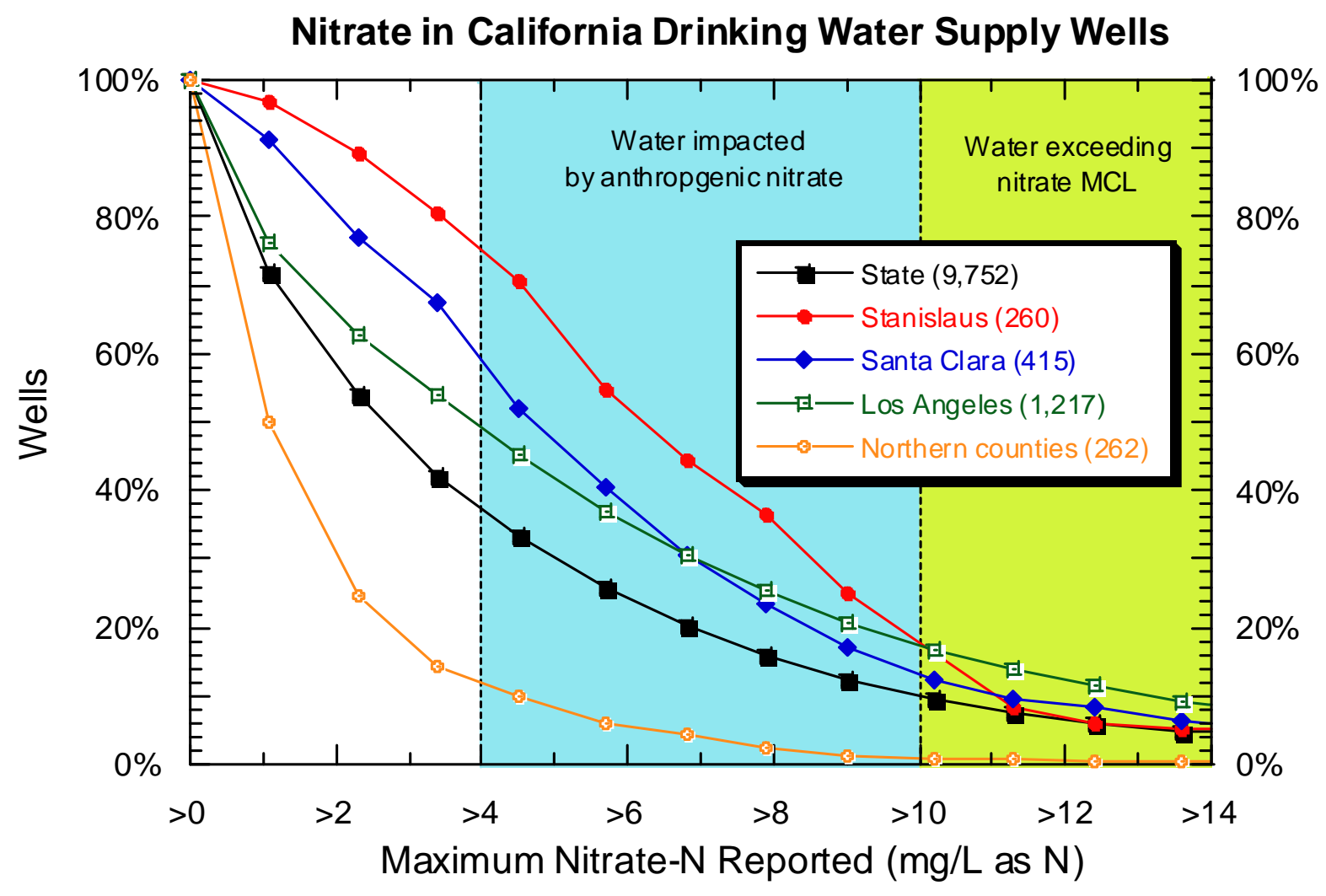

Figure 2. Maximum nitrate- $\mathrm{N}$ groundwater concentrations for drinking water wells in the Geotracker DHS database. The number of wells sampled is shown in the legend. Northern counties include Shasta, Mendocino, and Trinity. In blue are wells with maximum nitrate-N levels that do not exceed drinking water standards, but that do have elevated nitrate relative to average groundwater (Nolan et al., 2002; Squillace et al., 2002).

The DHS database utilized by Geotracker contains data from public drinking water supply wells and is biased toward deep groundwaters. Shallow groundwaters are much more likely to be impacted (Nolan, 1999; Nolan, 2001; Nolan et al., 1997; Nolan and Stoner, 2000). As an example, shallow groundwaters in almond orchard areas of the San Joaquin and Tulare basins have a median nitrate concentration of $10 \mathrm{mg} / \mathrm{L}$ nitrate- $\mathrm{N}$. The median nitrogen loading from inorganic fertilizers in this area is high $(85 \mathrm{~kg} / \mathrm{ha})$. Assessment of groundwater nitrate using the DHS database is also biased by the abandonment or closure of high nitrate drinking water wells. In both cases, the true impact of nitrate contamination on the groundwater resource may be underestimated by this approach.

California surface waters are also impacted by nitrate contamination. Concentrations in general do not exceed the drinking water MCL for nitrate (Figure 3). The draft DHS limit for total N in blended water for groundwater recharge (California DHS, 2002), however, is set at a level 
sufficiently low ( $3 \mathrm{mg} / \mathrm{L}$ ) that it would preclude the use of a significant number of surface drinking water supplies for blending with recycled water and recharging groundwater aquifers. This statement holds true even for recycled water that has been polished by advanced methods such as RO and does not contain significant levels of nitrate. In the national NAWQA study, $25 \%$ of the streams included in the survey had flow-weighted total fixed nitrogen concentrations of greater than $3 \mathrm{mg} / \mathrm{L}$. A California example from the LLNL database is water from the Old River at the Contra Costa County Outtake (Figure 3). This outtake supplies water to Los Vaqueros Reservoir, and contains both nitrate and salinity below primary or secondary limits. Nitrate, however, exceeds the draft DHS regulation of groundwater recharge, and this water could not be used for blending recycled water for surface or subsurface recharge operations.

Nitrate and Chloride in California Rivers

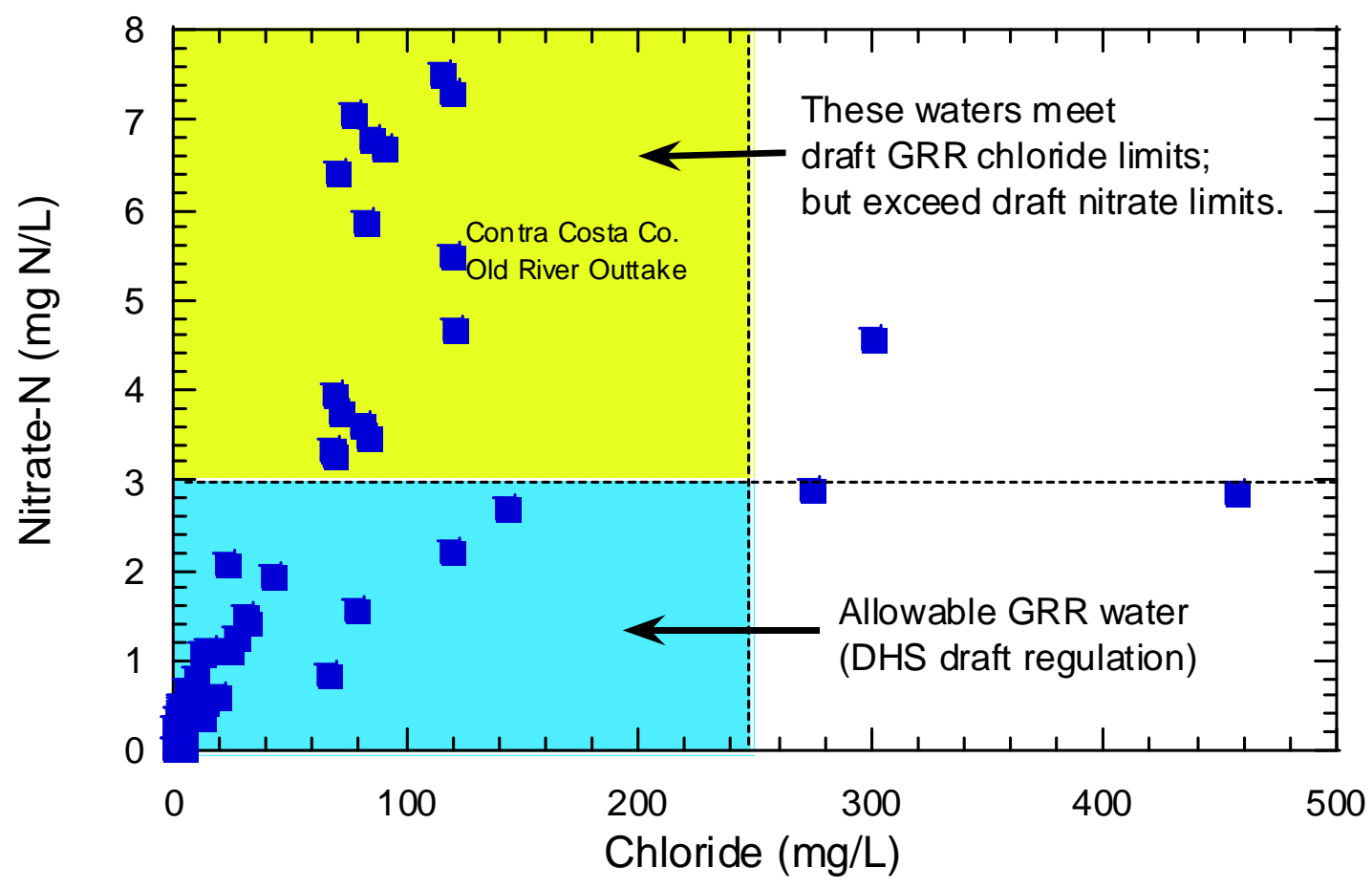

Figure 3. Nitrate and chloride concentration data from quarterly sampling of the major tributaries to the Sacramento-San Joaquin Delta (unpublished LLNL data)

More recently, the Natural Resources Defense Council highlighted nitrate contamination of State groundwaters in a report on "California's Contaminated Groundwater" (Helperin et al., 2001) and in "Cesspools of Shame" (Marks, 2001). The NRDC groundwater report concluded that agriculture and septic systems are the major sources of nitrate contamination, and illustrated the extent of the problem with the following observations: 
- Over the last decade, SWRCB 305(b) reports indicate that more than half of the areal extent of groundwater affected by major contamination is caused by agriculture and septic systems.

- For the period from October 1999 to October 2000, the DHS Drinking Water Database, which contains more than 7,100 distinct groundwater sources, lists nitrate was the number one contaminant.

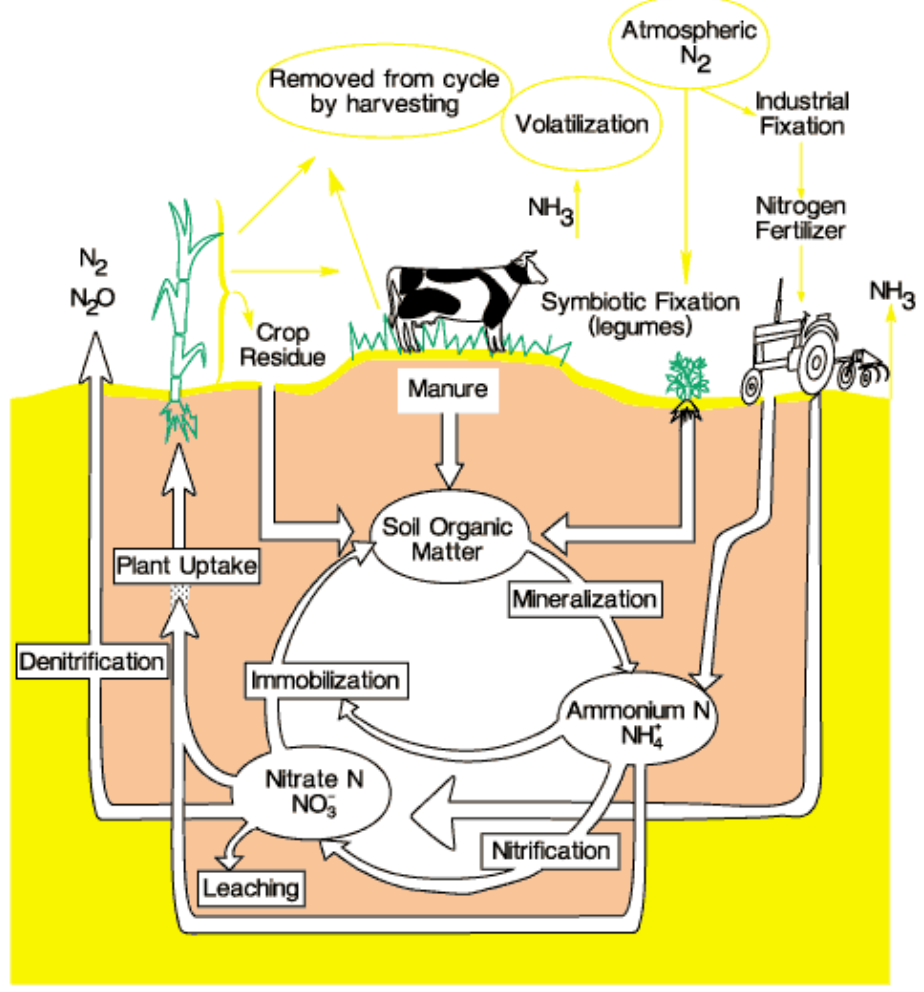

Figure 4: Nitrogen cycling in the soil and vadose zone in an agricultural setting. Not shown are septic system or wastewater treatment plant sources of nitrogen loading.

\section{Sources of nitrate contamination}

The 1988 SWRCB report (Anton et al., 1988) identified agricultural fertilization, animal operations (i.e. waste from dairy, feedlot, and poultry operations), and septic disposal systems as the three dominant sources of nitrate to impacted groundwaters in groundwater (Figure 4). Urban runoff and municipal waste treatment were cited as lesser sources. In 1988, the California Department of Food and Agriculture appointed a 12-member Nitrate Working Group consisting of individuals from agribusiness, State government, and the University of California. A year later, this group produced a report entitled “Nitrate and California Agriculture” (CDFA, 1989) which discussed agricultural and animal sources of nitrate, discussed best management practices (BMPs) to mitigate nitrate source loading and transport, and contained a description of factors important in making groundwater sensitive to nitrate. 
Fertilizer usage in California had doubled from 1950 to 1980 after which it leveled off at approximately 600,000 tons. Nationwide, nitrogen fertilizer use in the country increased over 300 percent from 1960 to 1988, with very little change in crop acreage and only a 40 percent increase in overall farm production. These figures indicate that nitrogen loading and leaching from a typical acre of fertilized farmland has increased dramatically. Field studies have shown that approximately one third of applied fertilizer is lost to leaching using older application methods. Furthermore, changes in fertilizer application may not be seen in groundwater for up to 60 years because of retention and cycling of fertilizer $\mathrm{N}$ in soil. Fertilizer application varies widely among crops, for example greenhouses and vegetable crops use more nitrate fertilizer than orchards and vineyards, and are associated with higher levels of nitrate in underlying groundwaters. Differences in crop type and fertilizer management should be taken into account in estimating source loading in any nitrate vulnerability assessment.

Dairy, cattle feedlot, and poultry operations are localized sources of potentially intense nitrate contamination. In 1988, milk production was the number one agricultural industry in California with over one million cows on over 2400 dairies. The dairy industry is concentrated in San Bernardino, Tulare, Stanislaus, Merced, Riverside and San Joaquin counties. Beef production is the number two agricultural industry in California with nearly 2.5 million cows in 1988 of which over half were raised on 38 feedlots in Imperial, Kern, Tulare and Merced counties. The development of dairy centers, such as has occurred in the Chino groundwater basin in southern California and in the Hilmar area of the San Joaquin Valley can have dramatic effects on groundwater quality. For example, groundwater nitrate- $\mathrm{N}$ in the Chino area more than doubled in less than 20 years (rising from 6 to $16 \mathrm{mg} / \mathrm{L}$ between 1969 and 1986). Dairy operations in California produced over 4 million tons of dry manure in 1997, a 50\% increase over 15 years. As livestock operations have become increasingly concentrated in California, manure production in affected counties has exceeded acreage available for application (Kellogg et al., 2000). So as with fertilization, although animal operations have existed in California since early in the State's history, dramatic changes have taken place in the last 50 years. The change in fertilization occurred earlier than the change in animal operations.

The US EPA has estimated that more than 1.3 million septic systems are in use in California. Nationwide, about a quarter of the population relies on septic systems, and about $6 \%$ of groundwater nitrate pollution is associated with septic discharge. The increasing density of these systems in California, especially in the Sierra foothills (e.g. the Chico area), indicates that nitrate problems associated with septic systems will increase. 


\section{Current Nitrate Management Efforts}

\section{Fertilizer Research and Education Program}

The "Nitrate and California Agriculture" report (CDFA, 1989) recommended that the CDFA facilitate the following activities:

- Identify nitrate-sensitive areas throughout the state (see Figure 1).

- Establish a list of priority areas in which nitrate control programs should be implemented

- Establish nitrate management programs in priority areas in cooperation with local government and agriculture,

- Develop best management practices to be incorporated into local nitrate management programs

- Establish a research and demonstration project on nitrate control through irrigation, fertilizer and manure management.

These recommendations became the mission of CDFA's Nitrate Management Program, which later developed into the Fertilizer Research and Education Program (FREP). FREP is funded by a mille tax on fertilizer (California Food and Agriculture Code, Div. 7, Chap. 5), and is advised by a Fertilizer Inspection Advisory Board that represents the agricultural community. Within the past year, one idea under consideration was a re-survey of nitrate contamination in State groundwater along the lines of the original 1988 SWRCB assessment. The purpose of the reassessment was to determine the effectiveness of 10 years of FREP research and public outreach into BMPs to mitigate nitrate pollution. The Board ultimately decided that such an assessment required resources and expertise not available to FREP (but would be available to the SWRCB), and would not answer the question as posed (Beam, 2002). The key mission of FREP continues to be research into best management practices and outreach with a focus on nitrate.

\section{Comprehensive Groundwater Monitoring}

In response to the discovery of MTBE, a gasoline additive, in public supply wells in a number of cities including Santa Monica, Los Angeles, and South Lake Tahoe, the California State Auditor issued a report (California State Auditor, 1998) that concluded that the State was lacking:

- An effective mechanism for the interagency coordination necessary for the early recognition and prevention of contamination of groundwater resources.

- The ability to easily identify the sources of groundwater contamination closest to drinking water wells and, therefore, prioritize the investigation or remediation based on this threat.

- The ability to provide drinking water regulators and water purveyors sufficient notification or details about contamination moving toward drinking water sources.

- A standardized database with a GIS interface that could streamline the integration of data from multiple agencies (i.e., it could integrate data for contaminant sites and drinking water sources) and give all stakeholders the information necessary to protect the beneficial uses of the State's groundwater. 
In January 2000, the SWRCB produced a plan for implementing a comprehensive program for monitoring ambient surface water quality and groundwater quality in response to supplemental language in the FY99 budget (California EPA, 2000a). The plan stated that features of a comprehensive ambient monitoring plan should include clear objectives, scientifically sound monitoring design, and meaningful indicators. On the last item, the Board stated "The ambient monitoring program should use the best available condition and response indicators of the environmental system. These indicators should be scientifically valid and practical, and they should address the needs of the water quality programs."

The SWRCB has overseen the development of a powerful database (and GIS interface) for groundwater, hydrogeologic, drinking water well, and contaminant release data. In addition, the SWRCB has developed working maps based on published literature identifying groundwater areas that are hydrogeologically most vulnerable to potentially contaminating activities. The SWRCB has worked, and will continue to work with DHS's Source Water Protection Program and DWR in a number of programs including the Bulletin 118 Update.

In October, 2001, The Governor approved Assembly Bill 599 (AB 599), establishing the Groundwater Quality Monitoring Act of 2001. The goal of AB 599 is to improve comprehensive groundwater monitoring and increase the availability of information about groundwater quality to the public. AB 599 requires that the SWRCB integrate existing monitoring programs and design new program elements, as necessary, to establish a comprehensive statewide groundwater quality monitoring program.

AB 599 also requires that on or before March 1, 2003, the SWRCB submit a report to the Governor and Legislature, detailing the following elements:

- A detailed description of a comprehensive groundwater quality monitoring program

- A description of how the program takes maximum advantage of existing information

- An assessment of additional monitoring necessary

- A specific set of recommendations for coordinating existing monitoring programs

- An estimate of funding necessary to implement the program

- Recommendations for an ongoing source of funds

- A prioritized list of actions to increase effectiveness of monitoring effort 


\section{An Approach to Manage Nitrate Contamination in Groundwater}

To adequately address nitrate contamination of groundwater, the State needs to be able to:

\section{- Characterize existing nitrate contamination in groundwater.}

We know that nitrate contamination of aquifers used to supply drinking water to the public is widespread. Although we know from the DHS Drinking Water Database how many wells have reported nitrate exceeding regulatory limits or at levels indicating anthropogenic input, we do not know what volume of water these reports represent. The abandonment of high-nitrate public drinking water supply wells only confounds estimation of total resource impacted. More importantly, our knowledge of nitrate contamination in shallow aquifers, which are expected to be preferentially affected by nitrate contamination, is limited. This is a significant information gap since these aquifers represent potential sources of contamination to deeper aquifers used for public drinking water, and are preferentially tapped by private wells for domestic use. Characterization of nitrate contamination within an aquifer involves determining the source, mechanism and history of contamination.

\section{- Assess the susceptibility of aquifers to future contamination.}

We know that the primary sources of nitrate contamination in groundwater are agriculture, animal operations, and septic systems. These sources are distinct from the industrial and commercial sources responsible for MBTE and solvent contamination, but do contribute to pesticide, pathogen and xenobiotic contamination. Accurately assessing the susceptibility of aquifers to nitrate contamination will require not only determining groundwater age (using the California Aquifer Susceptibility approach), but also capturing those parameters that are unique to nitrate. These will involve source loading, soil and surface nitrogen cycling (such as losses to plant uptake or to ammonia volatilization), and denitrification in the vadose zone or aquifer. Any risk or basin assessment model would need to address the distribution of sources (from point sources such as confined animal operations, to non-point sources such as irrigated agriculture to distributed sources such as septic systems), loading from these sources (using source type, the Agriculture Census, reported fertilizer sales, Air Board Emissions Inventories, etc), and transport between the surface and the water table. Transport of nitrate is important not only in evaluating the susceptibility of a pristine aquifer to nitrate contamination, but also in evaluating the time scale over which source controls will affect nitrate levels in a contaminated aquifer. In evaluating both uncontaminated and contaminated aquifers, the assimilative capacity of the aquifer for nitrate loading through denitrification also needs to be taken into account.

- Determine the best management strategy for contaminated and impacted aquifers.

Two important issues for the State to consider are how to prevent impacted aquifers from becoming contaminated, and how the remediate contaminated aquifers. The development of best management practices to mitigate nitrogen loading to susceptible aquifers is an area of active research. A number of models have been published that simulate nitrogen 
cycling at the field scale and predict nitrate leaching out of the soil zone under different agricultural management practices. Demonstration that predicted soil leach rates can be used as input to saturated zone nitrate models, and understanding how changes in field management practices affect aquifer nitrate concentrations is essential to the acceptance of these models in mandated nutrient management plans. Understanding aquifer assimilative capacity will be essential to setting acceptable nitrate leach rates in nutrient management planning. Remediation of contaminated aquifers is a difficult issue, and involves understanding the total cost of remediation.

To meet these goals, the State needs a toolkit with the appropriate tools (Figure 5). These tools should provide the State with a sound scientific rationale, clear objectives and meaningful indicators with which to assess groundwater basins (under the provisions of AB 599) and to institute a comprehensive monitoring plan for nitrate (as a component of GAMA). We believe that this toolkit should include the following:

- Groundwater basin assessment model

- A comprehensive monitoring plan

- An integrated GIS database and the appropriate database tools

- Denitrification assessment capability (excess $\mathrm{N}_{2}$, stable isotopes)

- Groundwater age-dating capability (tritium-helium, natural and introduced tracers)

- Source attribution capability (age, stable isotopes, nitrate co-contaminants)

- Co-contaminant characterization capability

- Nitrate management plan assessment model



Figure 5. The LLNL toolkit. 


\section{The Role LLNL Can Play}

LLNL has the expertise, and the analytical and computational capabilities to help the State build these tools. As a national security lab, LLNL has an unbiased view of energy and water issues in the State of California, and has the physical and personnel security to handle sensitive waterrelated data (e.g., DHS well locations). The purpose of this white paper is to discuss some gaps and opportunities in the current approach the groundwater nitrate problem in California, and to lay out how LLNL could assist the State Board in filling these gaps. The first section discusses the concept of assimilative capacity of aquifers for nitrate loading; the second section discusses nitrate co-contaminants; the third section discusses how to assess the success or failure of nitrate management plans, and the last section discusses groundwater basins assessment. In each of these sections, important concepts are discussed at a non-technical level, and potential tasks are sketched out. We can develop in detail any concept or task if requested by the Board.

LLNL has had a long and productive relationship with the SWRCB, with the major efforts being Geotracker under the LUSTIS program, and CAS under the GAMA program. These relationships are built on LLNL's expertise in environmental information systems and historical case analysis, on LLNL's special analytical capabilities \{e.g., a sophisticated ability to determine groundwater age (using the helium-tritium method) on time scales of interest to policy and management decision making\}, and on LLNL's ability to put together interdisciplinary project teams. This experience and these capabilities are applicable to the nitrate problem in California groundwater. In addition, LLNL has other analytical capabilities directly relevant to nitrate studies (e.g., precise determination of dissolved nitrogen gas in groundwater samples and characterization of trace organic compounds associated with nitrate contamination), and extensive knowledge of biogeochemical processes driving nitrogen cycling, particularly denitrification. Finally, LLNL has experience in characterizing and remediating nitratecontaminated groundwater (using phytoremediation, biodenitrification, ion exchange, and demonstration of natural attenuation) and in developing new contaminant remediation technologies (using membranes, electrochemical methods, and enhanced sorbents). 


\section{Specific Recommendations for Action}

\section{Conduct a Groundwater Basin Assessment of Nitrate Inventories and Impacts}

The ultimate goal of the Groundwater Quality Monitoring Act of 2001 (AB599) is the implementation of a comprehensive monitoring program to allow groundwater basin assessment. Assessment is a broad term still being defined by the AB599 Interagency Task Force and Advisory Board, but encompasses assessing susceptibility of groundwater to contamination, characterizing current water quality in a basin, and predicting future water quality under various conditions (including current conditions). To meet these goals, basin assessment must consider the current inventory of nitrate in basin soils and waters, current and past source loading, groundwater recharge and transport, and nitrogen cycling in the soil, vadose and saturated zone. In susceptibility assessment, index parameters are often sufficient; predictive modeling will require more detailed and accurate information.

\section{Nitrate as a contaminant}

As a contaminant, nitrate has a number of attributes that must be considered in constructing an assessment approach. The first set of attributes affect concentrations gradients within nitratecontaminated waters.

- Nitrate occurs naturally in groundwater at average ambient concentrations less than a factor of ten below the drinking water standard.

- Anthropogenic nitrate source loading is often low-intensity. For example, discharge from septic systems typically contains 30-110 mg/L nitrate+ammonia-N (Robertson et al., 1991), which on average is less than a factor of ten above the drinking water standard.

These factors combine to produce a groundwater concentration range that is often relatively narrow, even in contaminated systems. The assessment approach for a low-level contaminant such as nitrate will differ from the approach used for point-source industrial contaminants, which are often highly toxic and occur locally at extremely high levels. A nitrate assessment must distinguish between natural and anthropogenic nitrate and cannot use nitrate concentration alone as a susceptibility indicator (as can be done for volatile organic compounds).

- Anthropogenic nitrate has point (e.g. confined animal feeding operations), distributed (e.g. septic systems), and non-point (e.g. irrigated agriculture) sources

The distribution and strength of nitrate sources produce low level and pervasive groundwater contamination. These factors negate the utility of "plume mapping" in modeling nitrate contamination in many (but not all) instances.

The temporal distribution of nitrate also distinguishes it from many industrial contaminants. Most of the VOCs analyzed for CAS had widespread introduction into the environment more recently than nitrate. Only the trihalomethanes (drinking water disinfection by-products) likely have a similar time of appearance (about 100 years ago), and could be used for confirmation of transport from shallow sources greater than 50 years ago. Note, however, that in the last 50 
years, nitrate source loading in California has increased dramatically. Finally, nitrate and VOCs are labile under different conditions - for example, in fully-oxygenated groundwater, nitrate will behave conservatively

All of the factors discussed - spatial and temporal distribution of sources, the relative concentrations of nitrate in ambient and source waters, and the geochemistry of nitrate - have contributed to the pervasive low-level contamination of nitrate in California groundwaters that is now observed. GIS can be used to map in space and time both nitrate groundwater contamination and nitrate source loading. Corwin et al. (1997) have critically reviewed the peer-reviewed literature on modeling non-point source pollutants in the vadose zone and underlying groundwater with GIS.

We propose four efforts to assist the State in assessing groundwater basins to nitrate contamination. The first two efforts apply California Aquifer Susceptibility (CAS) data to susceptibility assessment with and without supplementary data. The remaining two efforts involve construction of a groundwater basin assessment model to characterize current and to model future nitrate distributions in California groundwater basins.

\section{Nitrate Susceptibility Assessment}

Some 20 models have been published with the capability of simulating nitrogen cycling in soils. A number of these are deterministic process-based solute transport models that predict nitrate buildup and leaching in the soil zone (e.g. LEACHN, NLEAP, GLEAMS, NCSWAP, etc), and are widely used in field-scale management of fertilizer and manure. Although they have been used to determine "nitrate leaching potential" or "groundwater pollution potential", validation and calibration has generally involved vadose-zone soil or water nitrogen data. Other approaches to susceptibility assessment require only property-based data, and include both index and regression models. These types of models are more applicable to systematic assessment of groundwater susceptibility at reasonable scales, and are discussed below.

\section{Previous nitrate susceptibility studies}

DRASTIC is a US EPA groundwater index model for assessing the potential of chemical impact over large areas using regional hydrogeologic settings (Aller et al., 1985, Aller et al., 1987, Deichert et al., 1992). DRASTIC is a mixture of intrinsic, specific, and extrinsic vulnerability methodologies, and employs a numerical ranking system that assigns relative weights to various parameters that help in the evaluation of relative groundwater vulnerability to impact. In one of the earliest applications of the DRASTIC approach to actual individual well data, Baker et al. (1990) found high positive correlations between Ohio county-averaged DRASTIC scores and concentrations of nitrate plus nitrate-nitrogen in samples of groundwater used to water livestock.

Richards et al. (1996a; 1996b) examined well construction, soil type, and land use as indicators of nitrate concentration in Midwestern agricultural and domestic well waters. They found that old, shallow wells developed in sandy soils in close proximity to feedlots, croplands, or agrichemical storage produced the highest nitrate waters. They also concluded that county-level DRASTIC scores were not good predictors of herbicides or nitrate in the study area.

Tesoriero and Voss (1997) studied the occurrence and distribution of elevated nitrate concentrations in groundwater in the Puget Sound Basin in Washington State. Using a logistic regression analysis, they found that the variables that best predicted elevated nitrate 
concentrations were well depth, land use and hydrogeology. Logistic regression analysis is an $a$ priori approach for assessing intrinsic and specific vulnerability, and doe not depend on qualitative assignment of index weights as does DRASTIC. An inverse relationship existed between well depth and the probability of an event; coarse-grained alluvial deposits were positively correlated with impacts, while fine-grained glacial deposits were inversely correlated; and wells with a high percentage of agricultural and urban land use within $3.2 \mathrm{~km}$ were more susceptible. Tesoriero and Voss (1997) recommended that assessments be continuously updated as new data become available.

Lichtenberg and Shapiro (1997) assessed nitrate-N and applied regression analysis to assess possible correlation to fertilizer applications, sales, well depth, soil types, and land use. Deeper wells appear less vulnerable than shallow wells, and wells with septic tanks in the area were considered to be as vulnerable as wells associated with major crops such as corn (where one septic system is associated with as much leaching as one hectare of corn), and that a $1 \%$ increase in septic tanks result in a $1.1 \%$ increase in nitrate-N concentrations. Non-confined aquifers had significantly higher incidences of impact, on the order of 2.5 to 3.3\%. Livestock inventories showed no significant correlation due their presence.

More recently, the USGS has used NAWQA data from shallow groundwater aquifers to assess aquifer susceptibility to nitrate contamination (Nolan, 2001; Nolan et al., 2002; Nolan et al., 1997; Nolan and Stoner, 2000). These multivariate linear regression models use proxies for nitrogen input and aquifer vulnerability to surface contamination to predict the probability that groundwaters will have elevated nitrate concentrations. The model predictions were then tested against actual nitrate concentrations in basins not used in constructing the original model. Earlier versions of the model considered a number of factors controlling nitrate in groundwater. Nolan and Stoner (2000) found that nitrate groundwater concentration was dependent on nitrogen loading, soil type, aquifer permeability, recharge rate, and climate; that high nitrate correlated with well-drained soils, fractured bedrock, and irrigation; and that low nitrate correlated with poorly drained soils, greater depth to groundwater, artificial drainage systems, intervening layers of unfractured bedrock, low rate of groundwater recharge, and anaerobic conditions in aquifers.

The variables used in the most recent model (Nolan et al., 2002) included fertilizer N loading, percent cropland-pasture, percent well-drained soils, depth to seasonally high water table, and the presence or absence of rock fractures. A significant finding of these studies is that "vulnerability of ground water to contamination by nitrate depends not on any single factor but on the combined simultaneous influence of factors representing nitrogen loading sources and aquifer susceptibility characteristics” (Nolan, 2001).

As an example of how public agencies have used index methods to assess vulnerability, the Columbia Basin Ground Water Management Association (GWMA) has implemented a series of projects to reduce nitrate leaching into groundwater. An important component of the effort is targeting vulnerable areas using a "leachability" index. Their database combines land use practices including soil types, cultivated acres, crop rotations, irrigation patterns along with a nitrate leaching probability model within the area of the Columbia Basin GWMA. A key recommendation of the effort is proper irrigation water management in areas of porous soils and high nitrate loading. 


\section{The California Aquifer Susceptibility Assessment and Nitrate}

Like a number of contaminants of concern in California groundwater, anthropogenic nitrate has a surface source. The main goal of the CAS project is to identify areas where relatively rapid vertical communication occurs between surface contaminant sources and subsurface drinking water supplies. CAS uses groundwater ages (determined from tritium-helium dating) to provide a mean time of transport for recharging groundwater to a drinking water production well, and uses the occurrence of low-level volatile organic compounds (VOCs) to indicate that contaminant transport has occurred on a 50-year or shorter time scale. The fundamental premise of the CAS approach is that groundwater age can be used as a guide for assessing aquifer susceptibility to surface contamination. The widespread use of regulated chemicals has only occurred during the last 50 to 60 years (following World War II). Therefore, groundwater that has recharged during the past 50 years is considered susceptible to contamination by organics such as MTBE and chlorinated solvents.

The time markers for water and contaminant transport in CAS data can be leveraged to address the issue of widespread nitrate contamination in public drinking water wells. Groundwaters with integrated ages in excess of 50 years and no detectable VOCs would be considered less susceptible to nitrate contamination associated with the doubling of fertilizer usage in California between 1950 and 1980 or with the more recent expansion in the number and size of confined animal feeding operations in the State (Anton et al., 1988). Furthermore, the susceptibility of these older waters to future nitrate contamination may be mitigated by their age (allowing time for oxygen depletion and denitrification to occur), the presence of barriers to transport that may provide environments favorable to denitrification (such as continuous confining clay layers), and the larger recharge areas they represent as the result of mixing and dispersion. Shallow, lowcapacity domestic or agricultural wells are less likely to benefit from these mitigating factors than deeper, high-capacity production wells.

Groundwater age can be used for more than qualitative susceptibility assessment. Groundwater age provides an estimate of the mean rate of advective flow to a production well capture zone, which in a basin-wide survey would allow definition of the basin flow field and indicate where recharge is taking place. Furthermore, in-depth analysis of groundwater age data for a given well gives an estimate of the distribution of ages in the groundwater delivered from a production well (e.g., fractions of modern versus pre-modern), and could be used to estimate dilution of a surface contaminant (such as nitrate) in the water pumped from the well. Adding details regarding the spatial and temporal input of nitrate and on processes that may occur during recharge or transport (mainly denitrification) will strengthen the predictive capacity afforded by CAS results.

CAS data may also allow quantification of the natural or pre-anthropogenic nitrate component. Groundwater that is devoid of tritium, but contains no radiogenic helium $\left({ }^{4} \mathrm{He}\right)$ has an age range of 50 years to a few hundred years. Groundwater having a significant accumulation of ${ }^{4} \mathrm{He}$ has a large component of water older than a thousand years. The approximate level of nitrate that occurs naturally in an aquifer may be derived from nitrate measurements in this preanthropogenic groundwater.

\section{The LLNL approach to groundwater basin assessment}

Comprehensive groundwater basin assessment (i.e. susceptibility assessment, characterization and modeling) requires full integration of all relevant data. LLNL has developed a methodology 
for integrating data and developing conceptual models to study the fate and transport of chemicals in groundwater (Figure 11). This methodology consists of three main components

- a web-accessible, centralized database and GIS,

- data integration and visualization tools, and

- decision-support tools, including predictive modeling.

This systematic approach to data collection, retrieval, and analysis has proven crucial to the characterization and remediation of groundwater contaminants at two, large-scale groundwater restoration projects managed by LLNL for the Department of Energy (DOE). This same methodology could be provided to the State to develop basin assessment and nitrate management plans as mandated by AB-599.

\section{Centralized database and GIS}

The State has embraced the concept of a common database for groundwater data. The State has invested significant resources in developing GeoTracker to support its underground storage tank program (SWRCB, 2002). The purpose of GeoTracker, as established by state mandate (AB 592, SB 1189), is to investigate the feasibility of establishing a statewide GIS for leaking underground fuel tank sites. GeoTracker is the interface to the Geographic Environmental Information Management System (GEIMS), a data warehouse that tracks regulatory data about underground fuel tanks, fuel pipelines, and public drinking water supplies. LLNL has provided significant expertise in the development of GeoTracker and GEIMS. Pending legislation will require all available water data to be included in GeoTracker (AB599, AB2886). We are aware of several databases that could contain data relevant in evaluating nitrate distribution in groundwater from a state-wide perspective. These include databases maintained by the California EPA Department of Pesticide Regulation and California Air Resources Control Board, the California DHS's Office of Drinking Water, the California Department of Water Resources, and the USDA Natural Resources Conservation Service. Geotracker and GEIMS provides a centralized, GIS-database that could be expanded to support State officials and government scientists for developing and testing basin-scale assessment and nitrate management plans.

\section{Data integration and visualization tools}

LLNL has shown that the study of groundwater flow systems and contaminant transport requires the ability to integrate and visualize multiple independent data sets. Data integration and visualization tools developed at LLNL have been successfully applied to identify the major, groundwater flow-controlling features, or hydrostratigraphic units (HSUs) at two ongoing, largescale groundwater restoration projects (Figure 12). HSU analysis is the first step in an iterative process of developing and refining conceptual hydrogeologic models. The integration of geologic, hydrologic, and chemical data is the essence of hydrostratigraphic analysis. The main objective of this analysis is to identify the major geologic units that control groundwater flow at the appropriate scale. The same methodology could be applied by the State to identify basinscale HSUs for nitrate assessment and management where sufficient data exist.

The data requirements for HSU analysis are extensive, and may not be appropriate for initial basin assessment in data-sparse regions of the State. LLNL also has experience with simpler models that are fully three-dimensional. The Integrated Groundwater-Surface Water (IGSM) model was developed at UCLA in the late 1970's and is currently maintained by the California 
DWR. This model simulates both surface and subsurface flow, and forms the basis for the Central Valley Ground-Surface Model used by the U.S. Bureau of Reclamation.

\section{LLNL Groundwater Basin Assessment Approach}
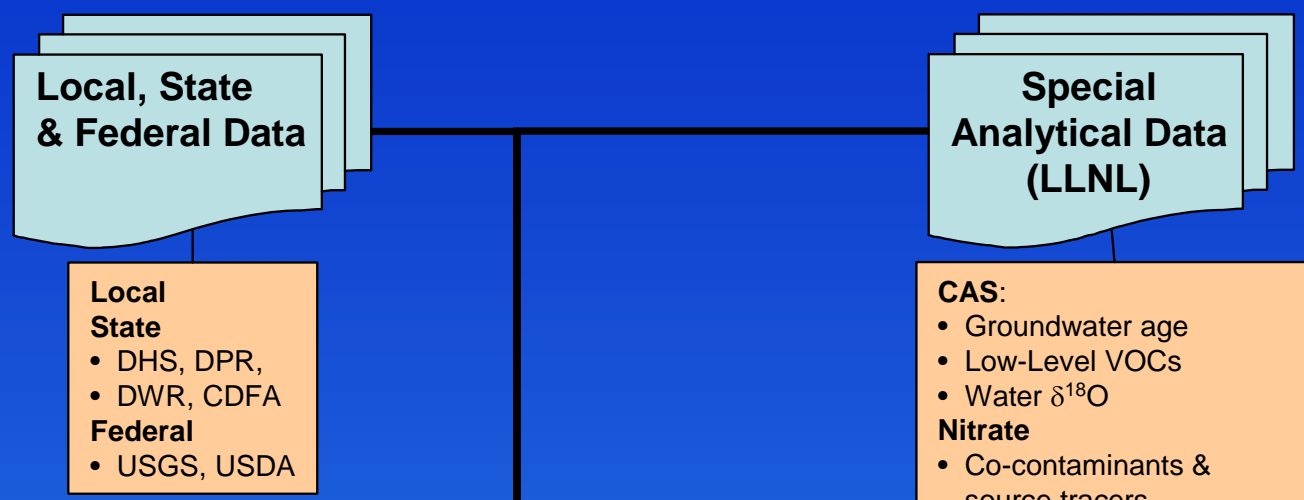

CAS:

- Groundwater age

- Low-Level VOCs

- Water $\delta^{18} \mathrm{O}$

Nitrate

- Co-contaminants \& source tracers

- Nitrate $\delta^{15} \mathrm{~N} \& \delta^{18} \mathrm{O}$

- Excess nitrogen

GEOTRACKER-like GIS:

- Well location, depth, construction

- Hydrologic and geologic data

- Nitrate concentration

- Groundwater age and chemistry

- Land use and nitrate source data

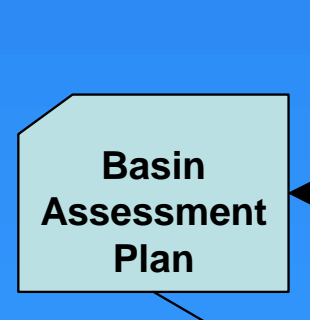

Database
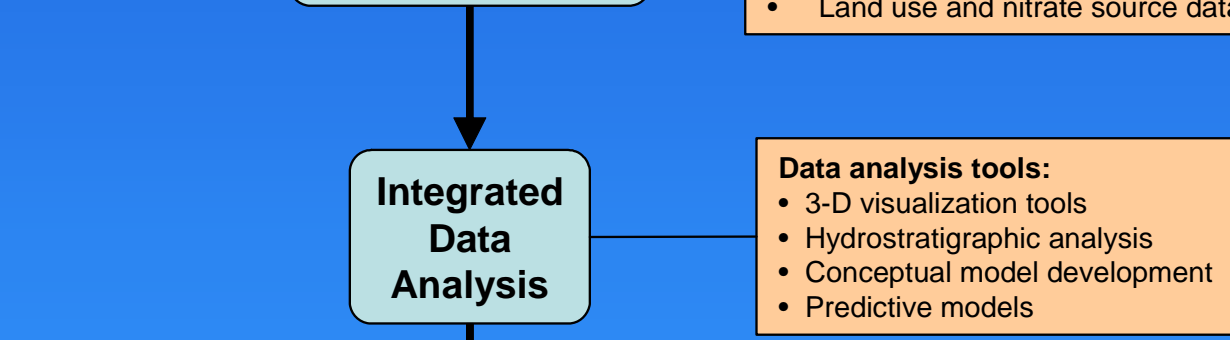

Mitigate aquifer nitrate loading

- Evaluate feasibility of treatment technologies

- Develop cost-effective remedial strategies

- Support farmers and irrigation managers

- Develop conjunctive use policies

- Protect water supply wells
- Predictive models

\section{Nitrate} Management Plan
- $\quad$ Mitigate aquifer nitrate loading

- Evaluate feasibility of treatment technologies

- Develop cost-effective remedial strategies

- Support farmers and irrigation managers

- Develop conjunctive use policies

- Protect water supply wells

Figure 11. The LLNL toolkit for groundwater basin assessment. 


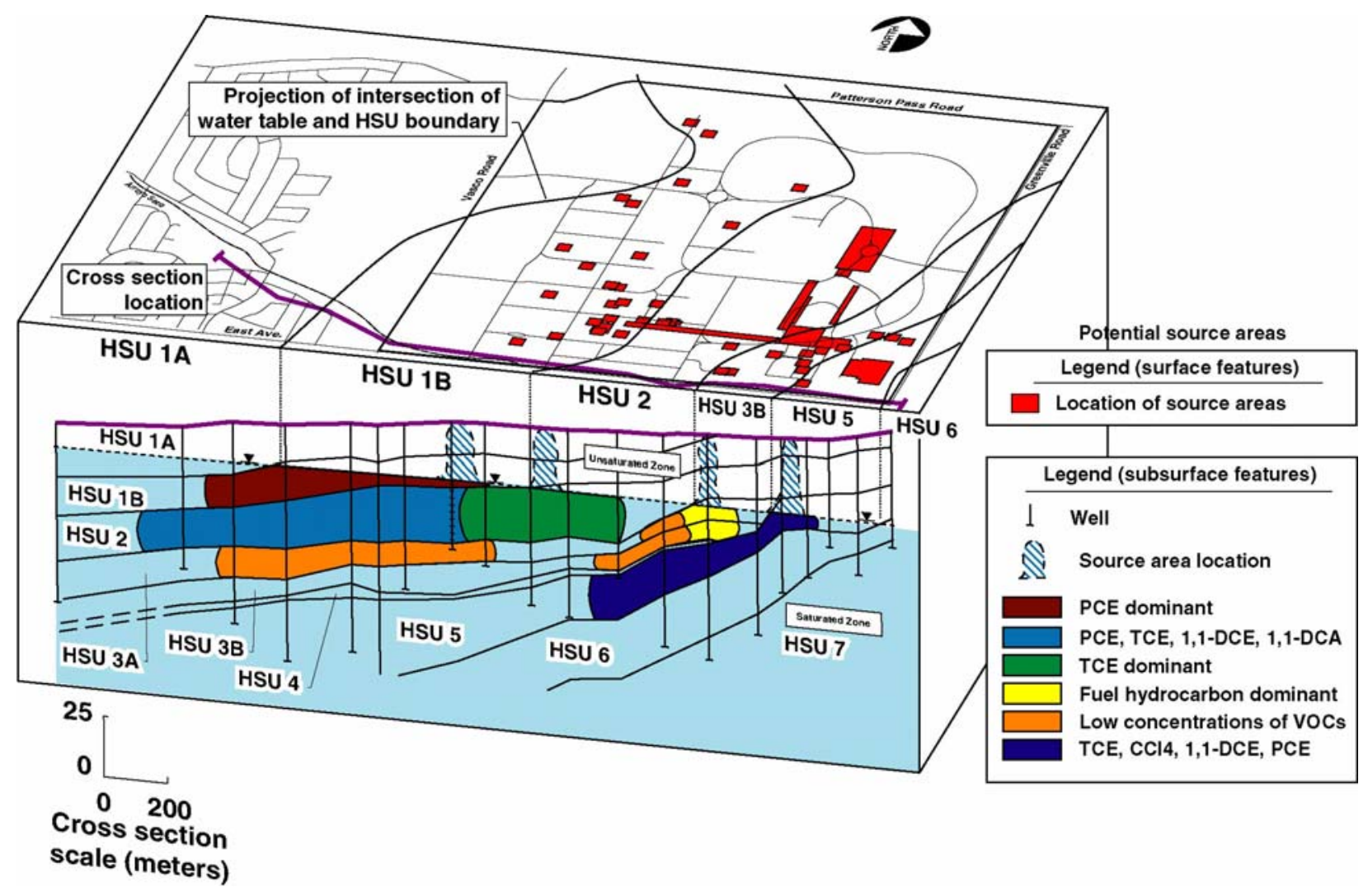

Figure 12. The Hydrostratigraphic Unit (HSU) approach to contaminant characterization as applied at the LLNL main site.

These data integration and visualization tools could also be used to:

- characterize temporal and spatial distribution of groundwater nitrate

- identify data gaps and improve monitoring,

- assess aquifer susceptibility,

- estimate nitrate loading to shallow aquifers,

- estimate volume of impacted groundwater, and

- identify vulnerable water-supply wells.

\section{Decision-making tools}

In addition to the integrated data analysis and visualization tools, basin-scale predictive models have been developed at LLNL to simulate groundwater flow and transport of contaminants, such as nitrate. These models include reactive transport processes to simulate oxygen consumption by 
aerobic microbial respiration and nitrate conversion to nitrogen by microbial denitrification. LLNL also has the expertise to improve the solute transport simulation capabilities of existing models such as IGSM. Predictive modeling is a critical decision-support tool for developing basin-specific assessment and nitrate management plans. For basin-specific assessment plans these models can be used to:

- improve conceptual models,

- predict the nitrate fate and transport under stressed and unstressed conditions,

- evaluate nitrate loading related to different agricultural practices, and

- predict nitrate concentrations at specific receptor points.

These predictive models can also be used as decision-support tools for nitrate management plans. For nitrate management plans these models can be used to evaluate different conjunctive use policies for surface and groundwater, and to evaluate the feasibility of different treatment technologies.

\section{Specific Tasks for Basin Assessment}

\section{Basin Assessment Task 1: Use the existing CAS dataset to assess groundwater susceptibility to nitrate contamination}

A cursory evaluation of CAS results and nitrate occurrence in drinking water wells shows that a slight expansion and further 'mining' of the CAS data set may be used to provide a predictive capability for identifying areas susceptible to nitrate contamination. A systematic correlation of nitrate concentration, groundwater age and VOC occurrence in drinking water aquifers would allow evaluation of the usefulness of the current CAS dataset in assessing groundwater susceptibility to nitrate contamination.

In the Livermore-Amador basin (Figure 13), the main conclusion from CAS is that wells in the eastern sub-basins, beneath the City of Livermore, are much more vulnerable to contamination due to relatively rapid vertical transport than wells from the Pleasanton side, where an effective confining layer prevents significant downward transport of water or contaminants (Moran et al., 2002). With reference to nitrate occurrence, the mean of the maximum nitrate- $\mathrm{N}$ concentration reported in 12 drinking water wells from the Livermore side of the basin is $9.9 \mathrm{mg} / \mathrm{L}$, with 6 wells above or near the MCL, while 13 wells from the Pleasanton side have a mean maximum of $16 \mathrm{mg} / \mathrm{L}$ and a highest reported value of only $5.2 \mathrm{mg} / \mathrm{L}$. (Nitrate loading may be higher in the Livermore area, as urbanization is somewhat less complete and occurred slightly later than for the Pleasanton area.) 


\section{Groundwater Age in Tri-Valley Public Water Supply Wells}

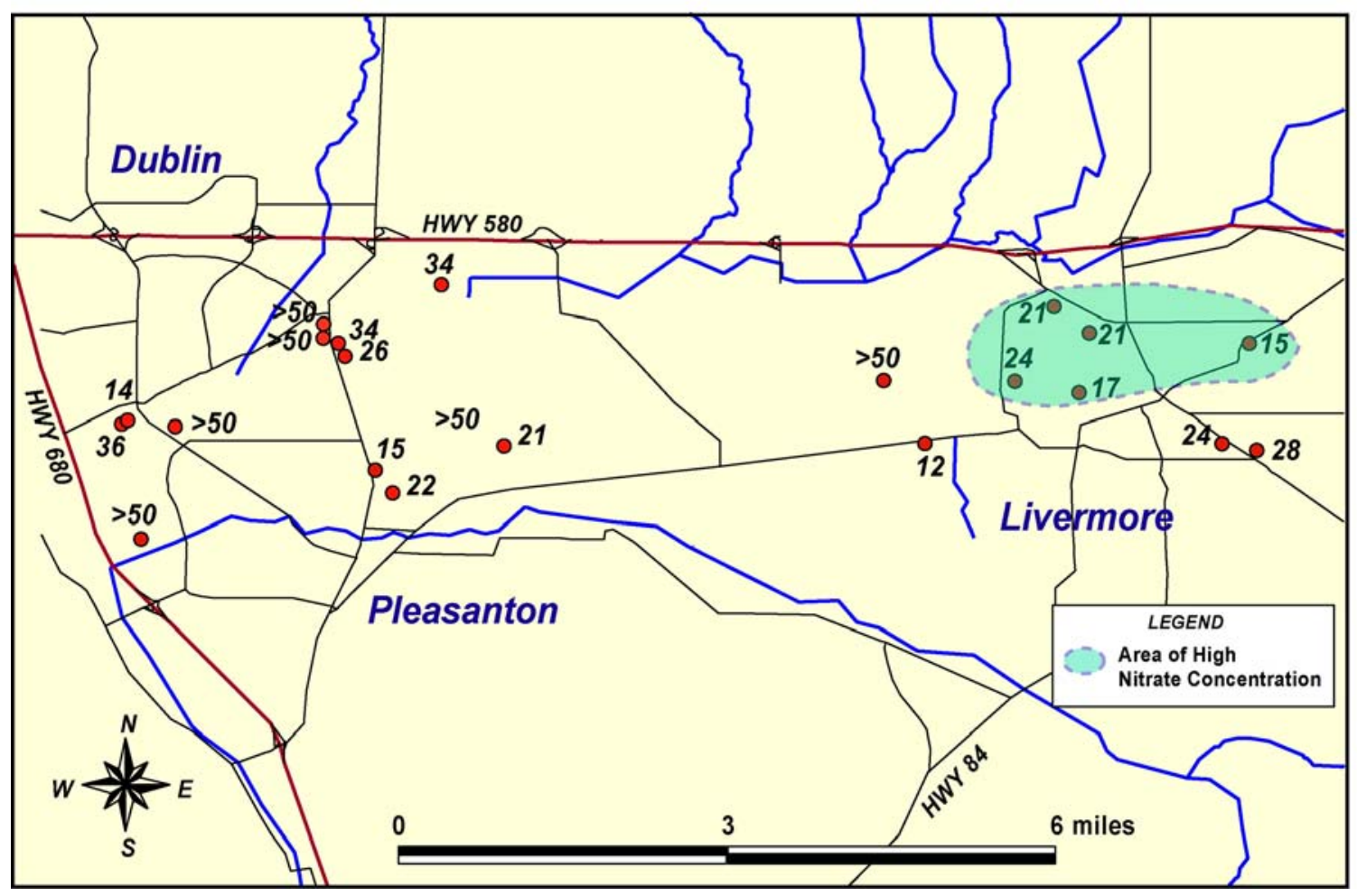

Figure 13. Groundwater ages (in years) in public drinking water supply wells in the Livermore-Amador Basin. Groundwater ages were determined using the tritium-helium method for the GAMA CAS project. High nitrate concentrations occur in shallower, younger waters in the eastern part of the basin.

\section{Basin Assessment Task 2:}

Import nitrate source data, soil data, and hydrogeologic basin data into the GEIMS database; and build data visualization and analysis tools for the Geotracker GIS

Geographic information systems are well suited for characterizing nonpoint source pollution contamination and sources. The current GEIMS database and Geotracker interface were designed to address groundwater contamination by industrial point sources. Future plans include incorporation of DWR data on lithology, screened interval, and depth to water table. Extending the approach to nonpoint-source agricultural contaminants such as nitrate requires data on the spatial and temporal input of nitrate, and on basin properties that affect the ultimate fate of nitrate (i.e. denitrification).

Parameters for susceptibility assessment and for predictive modeling of nitrate contamination fall into three classes: parameters related to groundwater recharge and transport, parameters related to nitrogen loading, and parameters related to nitrogen geochemistry. Ideal parameters would derive from existing data, be valid proxies for important fluxes or processes, and be available at an appropriate spatial scale for basin-wide studies. Parameters related to groundwater recharge and transport include soil characteristics (grain size, density, porosity), climate, depth to water table, well depth and construction, aquifer lithology, groundwater age, and the occurrence of 
recently introduced contaminants. Parameters related to nitrogen loading from agriculture include land use (row crops, orchards, vineyards, nurseries, pasture, and confined animal feeding operations), crop type, animal operation size and type (dairy, beef, swine, and poultry), fertilizer sales and application, and soil nitrogen surveys. Other proxies do exist. The CDFA found that irrigation water usage correlated with nitrogen loss from the soil zone. The California Air Resources Control Board has used animal population surveys to determine ammonia emission, which may be a useful proxy for nitrate loading from confined animal operations. Human population density is often used as a proxy for septic system density in rural or unincorporated areas. Parameters related to nitrogen cycling include soil organic matter content, groundwater oxidation state (DO, Fe, and $\mathrm{Mn}$ ), groundwater $\mathrm{DOC}$, depth to groundwater, and groundwater age.

The appropriate scale for susceptibility studies of deep groundwater in confined basins is not known, and may be limited by mixing and dispersion during recharge and transport. Using soils as an example, the USDA Natural Resources Conservation Service maintains several soil databases ranging in scale from national (NATSGO, 1:7,500,00 scale) to state (STATSO; $1: 250,000$ scale) to county (SSURGO; 1:12,000-1:63,360 scale). Wilson et al. (1996) found that the higher resolution of the SSURGO database was need to identify areas where surface loading of chemical contaminates are likely to contaminate shallow groundwater. Basin assessment of deep groundwaters should not require more finely resolved data, e.g. treatment of large confined animal operations as point sources or of septic sewer systems as a uniformly distributed nonpoint sources may be adequate.

Sources of data include local and regional agencies (water districts, vendors, regional boards and special districts), California state agencies (DHS, DWR, DPR, CARB, CDFA; agricultural extension services); and Federal agencies (USDA-NRCS, USDA Agricultural Census, USGS, USEPA). Parameters would be chosen based on pilot studies described below. A key component of this task would be development of data visualization tools, for which a GIS-based system such as Geotracker is especially well-adapted, and database management and analysis tools.

\section{Basin Assessment Task 3: Assess the susceptibility of groundwater basins and individual wells to nitrate contamination at a scale useful to basin management planning}

Current approaches to nitrate susceptibility assessment have limitations. The CAS approach does not include information specific to nitrate source loading or to denitrification in the soil, vadose or saturated zone. The NAWQA approach (Nolan, 2001; Nolan et al., 2002; Nolan et al., 1997) has limitations for application to basin-scale assessment of deep drinking water supplies in California. Input data are often at too coarse a scale (e.g. fertilizer nitrogen loading for an entire county), and the generated probability maps are intended for regional (multi-county) use. The nitrogen loading data do not distinguish between crop types, and septic systems and confined animal operations are not included in the assessment. Finally, the regressions were constructed against and for shallow aquifers, which are most vulnerable to nitrate contamination. Vulnerability factors and scale requirements may differ for deeper drinking water aquifers.

Supplementing CAS data with nitrate source loading and aquifer property data would be a powerful approach to assessing the susceptibility of groundwater basins to pervasive nitrate contamination. The technical approach would be basin-specific multivariate or logistic 
regression analysis using the parameters described in the preceding section, and nitrate occurrence. An important aspect of the final assessment tool would be the ability to visualize susceptibility in a GIS, and to determine and visualize uncertainty in the estimate. Corwin and Loague (Corwin et al., 1997; Loague et al., 1998) have argued convincingly that uncertainties arising from differences in the scales of sampling and system heterogeneity need to considered and quantified to make progress toward using GIS-based approaches to non-point source pollution assessment and management.

\section{Basin Assessment Task 4: Characterize the distribution of anthropogenic and natural nitrate in groundwater basins and develop a comprehensive monitoring plan using existing data, simple hydrogeologic models and data visualization}

An important aspect of groundwater basin assessment is an accurate and complete characterization of contamination within the resource. A simple count of "hits" on active public drinking water supply wells is misleading in several ways. Abandonment of wells with high nitrate levels leads to an underestimate of contamination. Production wells often have long screened intervals that span several water-producing zones, and produce "mixed" waters that may contain low- and high-nitrate components. Basic hydrogeologic parameters such as total water produced, depth to screen, and aquifer lithology are often not compiled or easily available for individual wells. The natural nitrate component is also not generally known. All of these factors make estimating the volume of water impacted by nitrate contamination within a basin difficult. The problem is worse for shallow domestic and agricultural wells that not only represent a threat to human health, but also represent a threat to deeper public supply aquifers.

Compilation and integration of nitrate concentrations in water is an important first step. DHS data are already in the GEIMS database. Data from shallow domestic and agricultural wells are needed to accurately characterize nitrate distribution in the subsurface. Potential data sources include NAWQA data, the GAMA Voluntary Domestic Well program, regional water board nitrate studies and plans, and agricultural NPDES permits. The compilation of relevant hydrogeologic data (depth to screen, screened interval, lithology, water production rates, etc) into a single integrated and secure database is an important second step in characterization. These data can be used to construct simple three-dimensional models of each groundwater basin under consideration. Coupling these models (which are discussed in more detail below) with measured nitrate concentrations from individual wells would allow mapping of the distribution of nitrate in the aquifer and determination of the volume of water that exceeds the regulatory limit. The final step is determining the distribution of anthropogenic and natural nitrate in basin groundwaters. CAS and supplemental data (stable isotopes, source tracers) can be used to identify waters not impacted by anthropogenic nitrate, and can also be used to estimate mixing ratios between old and young water. The correlation of ambient nitrate concentrations with specific hydrostratigraphic units would allow mapping of natural and anthropogenic nitrate components within the basin.

A more refined assessment of affected volume will require a quantitative assessment of mixing in long-screened production wells, i.e. understanding how to use production well data in groundwater basin assessment. This approach would also allow development of a systematic approach to monitoring by identifying units within the basin where monitoring data would have the greatest impact on uncertainty. With the appropriate data analysis and visualization tools, 
water resource managers could use these models to make decisions regarding development of new wells, and remediation of contaminated wells.

\section{Basin Assessment Task 5: \\ Model the future distribution of nitrate in a groundwater basin and at an individual well under current conditions and under different management plans}

The most difficult and perhaps the most important aspect of groundwater basin assessment is developing a modeling capability to predict future changes in nitrate concentration at an individual well under current conditions or under various management plans. Such a capability requires a basin-scale model to simulate groundwater recharge and flow, and to simulate nitrogen loading, transport and geochemistry. A basin-scale model that couples reactive transport of nitrogen with surface water flows, recharge through the soil and vadose zone, and groundwater transport in the saturated zone is not available. Basin-scale models such as IGSM couple surface water and groundwater flow, but have limited solute transport capabilities. A number of fieldscale models exist that simulate nitrogen cycling in soils and the upper vadose zone. Integration of these capabilities would have enormous benefit. For nitrate management these models could be used to evaluate the effect of agricultural best management practices (by estimating source loading to the saturated zone), and to evaluate different conjunctive use policies for surface and groundwater (by modeling the effects of artificial recharge on nitrate concentrations in basin groundwaters). These models could also be used to site monitoring wells to reduce uncertainty in the model or to act as early-warning systems for production wells.

Modeling without measurement, however, is meaningless. Only carefully calibrated and validated models will be useful to management and policy decision makers. The use of CAS groundwater ages greatly increases the robustness of these models. The gradient of groundwater ages in a basin can be used to estimate the hydraulic conductivity field, and constrain or validate simulations of groundwater flow. The use of stable isotopes, excess nitrogen and source tracers to constrain nitrogen source and denitrification allows calibration and validation of reactive transport models.

LLNL would use groundwater transport and contaminant reaction models to simulate nitrate transport and denitrification at the basin scale. A major focus of this task would be determining the best way to handle reactive transport of nitrogen in the vadose and saturated zone at the basin scale. The models would be calibrated against the basin groundwater and aquifer properties and current nitrate distribution, and validated using CAS groundwater ages and results from denitrification studies. 


\section{Characterize and Quantify Aquifer Denitrification Assimilative Capacity}

\section{Denitrification: Background}

Denitrification is a microbially-mediated process that converts nitrate into nitrogen, a harmless gas that constitutes $80 \%$ of the atmosphere. Denitrification during recharge and in the saturated zone can mitigate nitrate contamination and thereby reduce risk associated with drinking water supplies. Understanding and quantifying denitrification in the saturated and recharge zone is important to accurately assessing groundwater basin response to nitrate loading, and to designing in situ approaches to remediation (i.e. monitored natural attenuation or enhanced biodenitrification).

Denitrification consists of a series of oxidation-reduction reactions that ultimately involve electron transfer between an electron donor and nitrate, the terminal electron acceptor. The reduction of nitrate to nitrogen gas can be represented as follows:

$$
2 \mathrm{NO}_{3}{ }^{-}+10 \mathrm{e}^{-}+12 \mathrm{H}^{+} \rightarrow \mathrm{N}_{2}+6 \mathrm{H}_{2} \mathrm{O}
$$

The electron donor may be organic matter or a reduced inorganic compound. Heterotropic denitrifying bacteria are abundant and utilize organic compounds as the electron donors; autotrophic bacteria are less abundant and utilize inorganic compounds. The overall reactions may be represented as follows:

Heterotrophic denitrification: $5 \mathrm{CH}_{2} \mathrm{O}+4 \mathrm{NO}_{3}{ }^{-}+4 \mathrm{H}^{+} \rightarrow 2 \mathrm{~N}_{2}+5 \mathrm{CO}_{2}+7 \mathrm{H}_{2} \mathrm{O}$

Autotrophic denitrification: $5 \mathrm{FeS}_{2}+14 \mathrm{NO}_{3}{ }^{-}+4 \mathrm{H}^{+} \rightarrow 7 \mathrm{~N}_{2}+10 \mathrm{SO}_{4}{ }^{2-}+5 \mathrm{Fe}^{2+}+2 \mathrm{H}_{2} \mathrm{O}$

For a given electron donor, denitrification is thermodynamically less favorable than oxygen consumption, but more favorable than iron (III) and manganese (IV) reduction. Typical concentration profiles in groundwater reflect a succession of electron acceptor use consistent with such thermodynamic principles (Lovley and Chapelle, 1995). Assuming that denitrifying bacteria are present in a nitrate-contaminated aquifer (which is highly likely for these widespread bacteria), the two most important parameters required for denitrification are (1) the presence of a suitable electron donor and (2) low dissolved oxygen concentration (i.e., anoxic or anaerobic conditions) (Korom, 1992). Most denitrifying bacteria are facultative anaerobes and will cease denitrification in the presence of oxygen. Denitrifying microbes isolated from marine, freshwater, and soil environments have very low oxygen thresholds (<0.6 mg/L) (Tiedje, 1988).

Electron donors used by most denitrifying bacterial species are organic compounds (which can be naturally-occurring or anthropogenic), and several studies have produced evidence that under oxygen-limited conditions, denitrification is limited by the availability of dissolved organic carbon in groundwater. Other studies have demonstrated the occurrence of in-situ denitrification in the absence of DOC, and have ascribed aquifer reducing capacity to reduced aquifer solid phases acting as electron donors (e.g., iron sulfide minerals such as pyrite). 


\section{Denitrification in the Saturated and Vadose Zone}

Denitrification has been long recognized as an important process in the soil zone, in manure and fertilizer management, in wastewater treatment, and in both in situ and ex situ treatment of nitrate-contaminated groundwater. Although the existence of denitrification in the saturated zone and deep vadose zone has long been known, its quantitative impact on the nitrate budget of shallow groundwaters is only now being carefully assessed. Two examples will illustrate the extremes. A detailed nitrate mass balance model of loading to a shallow glacial outwash aquifer receiving significant agricultural input predicted nitrate concentrations that were three times higher than observed in the basin groundwaters (Puckett and Cowdery, 2002; Puckett et al., 1999). The difference was attributed to denitrification below the root zone, and the strong correlation of nitrate level with dissolved oxygen level supported this interpretation. The median DO level for this system was $3.6 \mathrm{mg} / \mathrm{L}$ with a wide range. In a study of denitrification rates in a very shallow sandy aquifer receiving discharge from a sewage treatment plant, Desimone and Howes (1996) estimated that although a sizable anoxic plume developed, denitrification accounted for less than $10 \%$ removal of the fixed nitrogen load. Denitrification was limited by depletion of dissolved organic carbon (not nitrate) concentrations.

These case studies demonstrate that subsurface denitrification can have a powerful mitigating effect on nitrate loading, but that the effect is likely to be basin- and source-dependent. We can capture this concept in the terms "basin denitrifying capacity" or "aquifer assimilative capacity". Previous assessments of aquifer vulnerability to nitrate contamination have used various proxies for the denitrification potential of a groundwater system (i.e., both the saturated zone and recharge zone). Nolan (2001) used percent organic matter in soils in combination with depth to the seasonally high water table to indicate conditions conducive to denitrification during infiltration. The Minnesota Ground Water Monitoring and Assessment Program used a different approach and defined "nitrate-stable" waters as those waters with high $\mathrm{E}_{\mathrm{H}}(>250 \mathrm{mV})$, elevated dissolved oxygen $(>0.5 \mathrm{mg} / \mathrm{L})$, and low dissolved iron concentration $(<0.70 \mathrm{mg} / \mathrm{L})$, based on correlations between nitrate and these parameters in Minnesota drinking water supply wells.

A number of other researchers have also noted that groundwaters that contain elevated levels of dissolved $\mathrm{Fe}^{2+}$ and $\mathrm{Mn}^{2+}$ contain low nitrate, an observation consistent with the solubility of reduced $\mathrm{Fe}$ and $\mathrm{Mn}$ in the absence of dissolved oxygen or sulfide. Panno et al. (2001), for example, characterized nitrate contamination in the Chalk Aquifer, a confined carbonate aquifer that supplies $50 \%$ of the United Kingdom's potable groundwater, and observed that groundwaters with measured Pt-electrode $\mathrm{E}_{\mathrm{H}}$ values below $250 \mathrm{mV}$ contained undetectable levels of nitrate, and that elevated levels of $\mathrm{Fe}^{2+}(>1 \mathrm{mg} / \mathrm{L})$ and $\mathrm{Mn}^{2+}(>0.1 \mathrm{mg} / \mathrm{L})$ only occurred in low-nitrate waters. In the Geotracker DHS database, $17 \%$ of California drinking water supply wells report maximum $\mathrm{Fe}^{2+}$ concentrations of greater than $0.70 \mathrm{mg} / \mathrm{L}$, and $21 \%$ of the wells report $\mathrm{Mn}^{2+}$ concentrations of greater than $0.1 \mathrm{mg} / \mathrm{L}$. These wells may draw on aquifers with the capacity to reduce nitrate. The use of Fe and $\mathrm{Mn}$ data alone to indicate the absence of oxygen, however, may underestimate the number of groundwater systems capable of supporting denitrification. A groundwater may contain low or no oxygen and low levels of Fe and $\mathrm{Mn}$, because of the paucity of $\mathrm{Fe}$ and $\mathrm{Mn}$ solid phases in aquifer solid phases or because of precipitation of insoluble sulfide phases under extremely reducing (i.e., sulfidogenic or methanogenic) conditions.

Groundwater dissolved oxygen, when determined accurately, may be a useful indicator of aquifer assimilative capacity if the following issues are considered. Water sampled from 
production wells with long screened intervals comprises a mixture of ambient groundwaters, some of which may be sufficiently devoid of oxygen to support denitrification. Even for water from a discrete sampling interval, in-situ mixing between low-oxygen and high-oxygen groundwater (reflecting either regional hydrology or seasonal recharge patterns) can produce a mixed groundwater that contains both oxygen and nitrate, but which has experienced denitrification. And finally, low-oxygen microenvironments in saturated aquifers (e.g. "deadend" porosity in fine-grained carbonate and clastic sediment, see Mariotti et al., 1988) may support much higher levels of denitrification. For these reasons, a direct application of the microbial threshold for denitrification (e.g. $0.6 \mathrm{mg} / \mathrm{L}$ ) may not be appropriate. Field studies have found evidence for denitrification in waters containing up to $2 \mathrm{mg} / \mathrm{L}$ oxygen (see Korom, 1992). As discussed above, the data from these field studies do not necessarily indicate microbial denitrification at oxygen levels above laboratory-observed thresholds. A viable approach to determining the value of dissolved oxygen for basin assessment of assimilative capacity would be to correlate it against direct evidence for denitrification (e.g., excess nitrogen gas).

Many of the studies of denitrification in the saturated zone have been sited in shallow and young groundwater systems affected by industrial or wastewater contamination. Groundwater pumped from California drinking water supply wells is generally deeper and older. The age of deep groundwaters allows time for oxygen depletion by aerobic microbial oxidation of dissolved organic carbon (or another appropriate electron donor). In the absence of a systematic survey of ambient oxygen levels in California groundwaters, oxygenation in deep drinking water aquifers cannot be assumed. Although alluvial aquifers in the Central Valley are often well oxygenated, examples of low oxygen waters do exist in both shallow and deep aquifers.

\section{Methods for characterizing denitrification}

A number of approaches have been used to characterize denitrification in the subsurface. Enzyme inhibition (e.g., the acetylene block), incubation and ${ }^{15} \mathrm{~N}$ tracer methods are not applicable to a monitoring or basin assessment approach to nitrate characterization (see, e.g., Desimone and Howes, 1996). They require access to aquifer materials or very closely spaced well arrays, and integrate denitrification rates over short spatial and temporal scales. Detailed nitrate budgets that ascribe the discrepancy between predicted and observed nitrate concentrations in receiving waters to denitrification provide only indirect evidence for denitrification.

At the watershed or basin scale, denitrification can be demonstrated by correlations between of low nitrate concentration with reducing conditions (e.g., low dissolved oxygen, high $\mathrm{Fe}^{2+}$ and $\mathrm{Mn}^{2+}$ ) and the presence of an electron donor (e.g., dissolved organic carbon), or by the loss of nitrate along a groundwater flow path. Flowpath arguments are more convincing if the appropriate conditions are present for denitrification, and if dilution by mixing or dispersion can be eliminated or quantified. Certain geochemical changes, such as an increase in alkalinity accompanying oxidation of organic matter, may also occur during denitrification, and be seen along a flowpath or correlated with nitrate concentration.

\section{Excess Nitrogen}

Attributing nitrate concentration trends to denitrification is always confounded by uncertainties in mixing, dispersion, and accurate assessment of the hydrogeologic regime. The need to 
distinguish degradation from simple dilution is common to any study of "natural attenuation". The most robust and conceptually simplest remedy is demonstrating that contaminant loss is accompanied by accumulation of an end product. For denitrification, the end product is nitrogen gas. Dissimilatory nitrate reduction to ammonia does occur, but under much more limited conditions than reduction to nitrogen gas. In past studies, the use of nitrogen to demonstrate denitrification has been limited by the difficulty in determining the "atmospheric" nitrogen component. All groundwater contains dissolved atmospheric gases in excess of concentrations predicted by equilibrium solubility control. The variable concentration of atmospheric nitrogen in groundwater makes determination of "excess nitrogen" produced by denitrification uncertain if only nitrogen is measured. If other atmospheric gases, such as argon, are measured, then a correction can be made (Figure 6). An advantage of the excess nitrogen method is that the total amount of nitrate reduced can be determined under conditions that retain nitrogen in solution, e.g., in confined aquifers. And in age-dated waters, knowing the total amount of nitrate reduced allows calculation of a denitrification rate, an important parameter in any model of nitrate fate and transport in a groundwater basin.

Previous excess nitrogen studies have used gas chromatography and/or mass spectrometry. Both methods require extraction of a gas sample, a step that adds time and can limit precision. Membrane inlet mass spectrometry (MIMS) is a new method in this field and allows precise and fast determination of the concentrations of nitrogen, oxygen and argon dissolved in groundwater samples without a separate extraction step (Kana et al., 1994). The MIMS method has been used to determine denitrification rates in estuarine waters, but to our knowledge, we are the first group to use the method for groundwater denitrification studies. A water sample at atmospheric pressure is drawn through a thin silicone rubber tube inside a vacuum manifold. Dissolved gases readily permeate through the tubing into the analysis manifold, and are measured using a quadrupole mass spectrometer. The technique is fast, precise and accurate, and can be used in the field. The method is also robust, which will allow widespread use by trained operators. One advantage for denitrification studies is that dissolved oxygen content can be determined accurately at the same time as "excess nitrogen". 


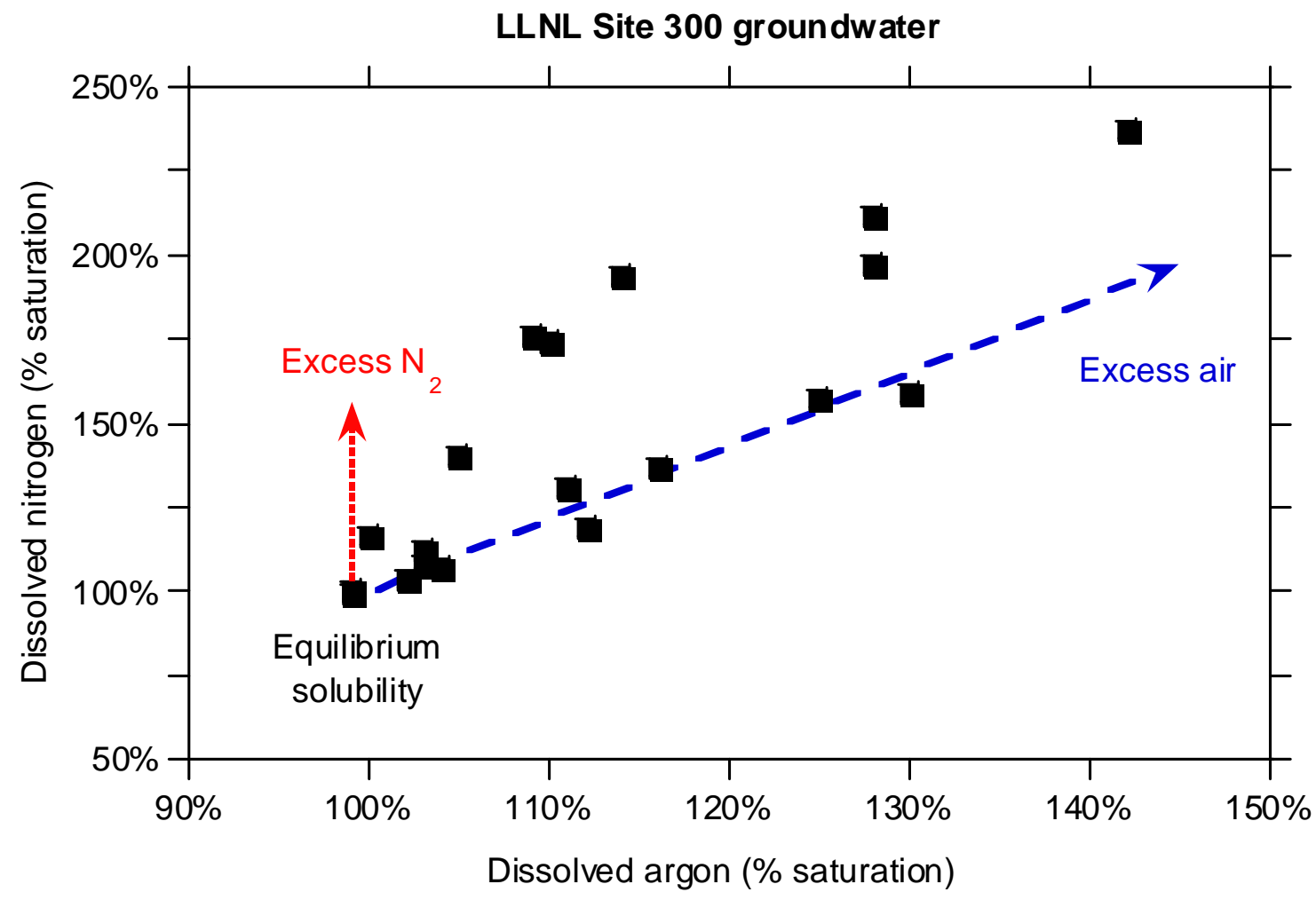

Figure 6: Groundwater nitrogen and argon in groundwaters from Site 300 (near Tracy, CA). Dissolved gas concentrations were determined by MIMS at LLNL. Samples with "excess nitrogen" (produced by denitrification) plot above the blue mixing line between equilibrium solubility and "excess air" (entrained in groundwater during recharge). Units are expressed as percent saturation with respect to a water standard at $20^{\circ} \mathrm{C}$ and $300 \mathrm{~m}$ elevation.

\section{Stable Isotopes of Nitrate}

Stable isotope ratios of nitrogen and oxygen in nitrate have been used for over a decade to demonstrate the occurrence of denitrification in groundwater (Böttcher et al., 1990; Kendall and McDonnell, 1998). Stable isotope composition is expressed using delta notation, which is the per mil (\%) difference between a sample atom ratio and a standard atom ratio.

$$
\begin{aligned}
& \delta^{15} \mathrm{~N}=\left\{\left({ }^{15} \mathrm{~N} /{ }^{14} \mathrm{~N}\right)_{\text {sample }} /\left({ }^{15} \mathrm{~N} /{ }^{14} \mathrm{~N}\right)_{\text {standard }}-1\right\}^{* 1000} \\
& \delta^{18} \mathrm{O}=\left\{\left({ }^{18} \mathrm{O} /{ }^{16} \mathrm{O}\right)_{\text {sample }} /\left({ }^{18} \mathrm{O} /{ }^{16} \mathrm{O}\right)_{\text {standard }}-1\right\}^{*} 1000
\end{aligned}
$$

Light isotopes, including those of $\mathrm{N}$ and $\mathrm{O}$, are fractionated during chemical transformations such as denitrification. In particular, denitrification results in an exponential increase in $\delta^{15} \mathrm{~N}$ of residual nitrate with decreasing nitrate content. Denitrification likewise causes an increase in the $\delta{ }^{18} \mathrm{O}$ of the residual nitrate. The ratio of enrichment of oxygen to nitrogen is consistent across environmental settings, and has been empirically determined to be 1:2 (Figure 7). Thus, while the starting isotopic composition of nitrate in groundwater may appear almost anywhere on a $\delta$ ${ }^{15} \mathrm{~N}$ vs. $\delta{ }^{18} \mathrm{O}$ plot, denitrification over time or along a flowpath is demonstrated by the positively sloped vector on the same plot. One of the most useful applications of the "dual isotope" approach is to distinguish between mixing of two nitrate sources (usually a natural component 
low in nitrate and depleted in ${ }^{15} \mathrm{~N}$ and one high in nitrate with higher $\delta{ }^{15} \mathrm{~N}$ ) and denitrification. In addition, once denitrification is documented, one can back-extrapolate to estimate the original isotopic composition of the nitrate source(s).

\section{LLNL Site $\mathbf{3 0 0}$ groundwater nitrate}

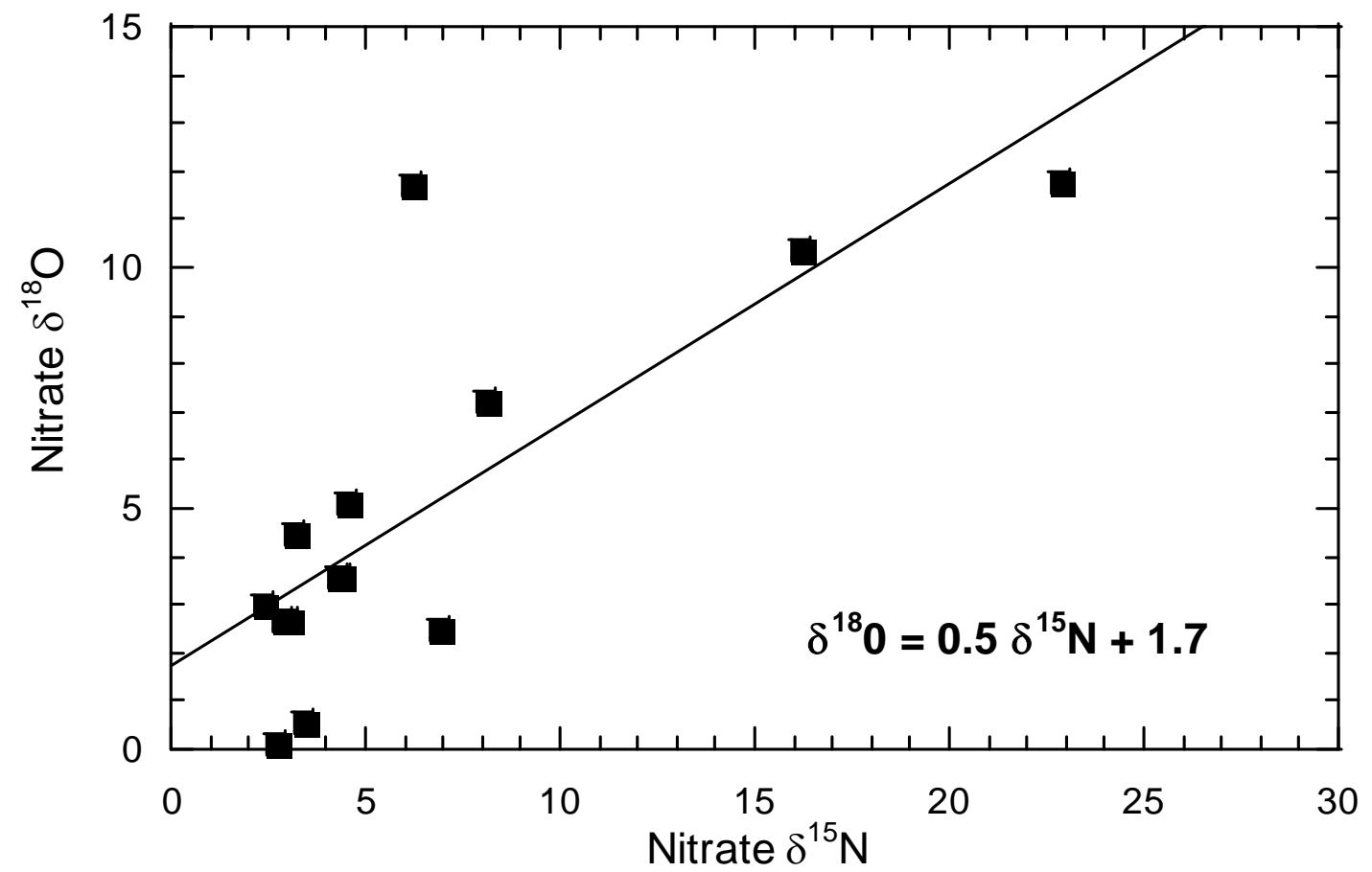

Figure 7: Nitrate $\delta^{15} \mathrm{~N}$ and $\delta^{18} \mathrm{O}$ in groundwaters from the Tnbs2 aquifer at LLNL Site 300 (near Tracy, CA). These samples show the characteristic trend of 1:2 for denitrification.

\section{A Case Study: LLNL Site 300}

LLNL researchers have successfully used the dual-isotope and excess nitrogen approach to demonstrate in situ denitrification in anoxic waters of an aquifer underlying Site 300 (near Tracy, CA). In these studies, a compilation of several kinds of data was used, including nitrate and DO concentrations, $\delta^{15} \mathrm{~N}$ and $\delta^{18} \mathrm{O}$ ratios in groundwater nitrate, excess nitrogen in groundwater (by MIMS), and hydrogeologic characterization. In one zone of the aquifer, nitrate concentrations decreased from $>100 \mathrm{mg} \mathrm{NO}_{3}{ }^{-} / \mathrm{L}$ to undetectable levels when the groundwater entered a confined region. In nitrate-depleted groundwater samples from the confined region, low DO and high excess nitrogen concentrations were found (Figure 8) In addition, the trend of $\delta^{15} \mathrm{~N}$ and $\delta^{18} \mathrm{O}$ ratios in nitrate were consistent with denitrification, having a ratio of 1:2 (Figure 6). Notably, enrichment of nitrate $\delta^{15} \mathrm{~N}$ and $\delta^{18} \mathrm{O}$ correlated with decreasing nitrate and increasing excess nitrogen concentrations in the confined region (Figure 8). Since dissolved organic carbon (DOC) concentrations are relatively low in this aquifer, it is likely that pyrite, a prevalent mineral in this aquifer, is serving as the electron donor; in situ denitrification relying on pyrite as the 
electron donor has been reported for various aquifers (Kölle et al., 1985; Pauwels et al., 1998; Postma et al., 1991). This study highlights the robustness of the dual-isotope and excess nitrogen approach, and indicates that under certain settings, denitrification in confined aquifers is not necessarily limited by dissolved organic carbon.

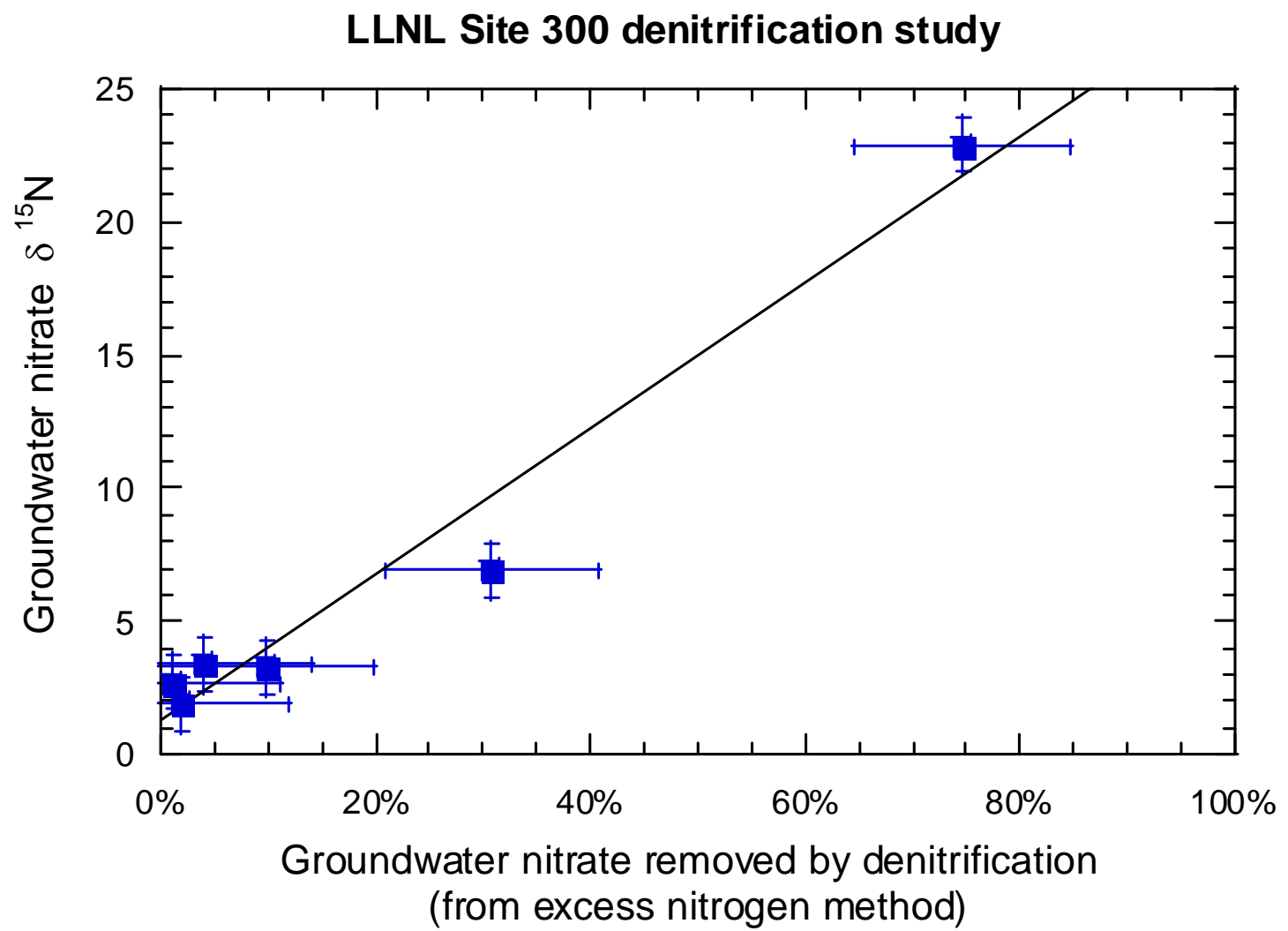

Figure 8: Nitrate $\delta^{15} \mathrm{~N}$ and nitrate removal in groundwaters from Site 300 (near Tracy, CA). The fraction of nitrate loss to the system by denitrification was assumed to equal the following ratio: excess nitrogen$\mathrm{N} /$ measured nitrate- $\mathrm{N}+$ excess nitrogen- $\mathrm{N}\}$.

The use of the excess nitrogen approach, especially in conjunction with the dual isotope approach is a powerful tool that gives us the ability to determine the occurrence and degree of denitrification in a groundwater sample. With a groundwater transport model and groundwater age-dating, we can then determine average in-situ denitrification rates, and the total flux of fixed nitrogen to the saturated zone. These are important parameters in groundwater basin assessment, and for more detailed basin studies of artificial recharge or nitrate management impact.

\section{Specific Tasks for Aquifer Assimilative Capacity}

A number of efforts, listed below, would allow the SWRQB to assess the value of characterizing denitrification, with respect to groundwater basin assessment and nitrate management for resource protection. Brenda Erkwurzel, a professor at the University of Arizona, has committed a 
graduate student to working on denitrification in groundwater basins, and would like to collaborate with LLNL.

\section{Aquifer Assimilative Capacity Task 1:} Characterize denitrification in a subset of GAMA wells

A subset of wells from both the CAS and Voluntary Domestic Well program could be characterized for excess nitrogen, dissolved oxygen (DO), and nitrate $\delta^{15} \mathrm{~N}$ and $\delta^{18} \mathrm{O}$ using MIMS and isotope ratio mass spectrometry. Ancillary properties such as dissolved organic carbon, ammonia, nitrate and nitrite, dissolved iron and manganese would also be determined using standard methods if not otherwise available. Wells would be chosen to adequately represent expected differences in nitrate loading and source; groundwater depth, age, geochemistry, and DO concentration; and aquifer and recharge zone properties (thickness, lithology, transport and recharge rates, hydrostatic head).

The end product would be a representative dataset of denitrification in California drinking water groundwater basins, and would provide an assessment of the prevalence of denitrifying conditions, limitations to denitrification (e.g., the presence of DO or the absence of DOC), and the suitability of different proxies for groundwater basin assessment (including $\mathrm{E}_{\mathrm{H}}$ or $\mathrm{DO}$ measurements made by water district or vendor personnel). The study would rate the effectiveness of each data type from this comprehensive approach. For example, the nitrogen isotopic data could be used to assess the value of a dual isotope approach in a monitoring framework. We expect that the isotopic data would allow quick identification of waters impacted by septic systems or animal operations, especially where denitrification in the saturated zone is minimal (as indicated by the excess nitrogen data).

\section{Aquifer Assimilative Capacity Task 2: Characterize denitrification during recharge and transport in individual groundwater basins}

Evaluate denitrification in an individual groundwater basin using excess nitrogen and the isotopic composition of nitrate in conjunction with groundwater age dating (by tritium-helium or tracer methods), characterization of groundwater chemistry and aquifer lithology, and hydrogeologic modeling.

The purpose of this study would be to characterize the occurrence and location of subsurface denitrification in an individual basin in order to understand controls on denitrification during recharge and groundwater transport, and be able to construct an accurate mass balance for groundwater basin nitrate. Different methods would be used to determine denitrification rate (degree of denitrification and groundwater age in individual samples, loss of nitrate along a flowpath, etc). An important outcome would be an estimate of denitrification rates for input into groundwater basin models of nitrate fate and transport, and validation of nitrate management models that predict nitrate leakage to the subsurface. Such studies would also help define the appropriateness of proxies for denitrifying capacity for different types of basins.

A number of basins would be appropriate for a trial study: basins receiving artificial or controlled recharge (e.g. northern Santa Clara Valley Water District), basins with documented 
nitrate problems (Central Valley basins receiving agricultural or dairy inputs, Sierra foothill basins receiving septic input), basins with Nitrate Management Plans (e.g. the Llagas subbasin in Santa Clara Valley), or basins with documented nitrate plumes of unknown provenance (e.g. the Livermore Buena Vista plume). A basin-scale study of denitrification would be most effective combined with a source attribution and/or nitrate management study.

The California Aquifer Susceptibility dataset would be invaluable in choosing study sites. As an example, drinking water wells serving the City of Lodi, solvents and/or the volatile pesticide DBCP were found in all but one of the 24 wells tested for CAS. The occurrence of DBCP is an indication of the impact of agricultural water on these wells, whose average depth is $450 \mathrm{ft}$. However, the mean maximum nitrate-N concentration reported to DHS is only $2.6 \mathrm{mg} / \mathrm{L}$, and no wells approach regulatory limits. The single well with no VOC detections also has the lowest reported nitrate maximum $(0.23 \mathrm{mg} / \mathrm{L} \mathrm{N})$. The low nitrate levels in wells affected by agricultural recharge and the very low nitrate levels in unaffected wells may result from denitrification.

\section{Aquifer Assimilative Capacity Task 3: Develop appropriate proxies for aquifer assimilative capacity in groundwater basin assessment}

An important task for developing a basin assessment approach to denitrification is to develop proxies for aquifer assimilative capacity using data from the Geotracker database, other Statewide databases (e.g. DWR lithology logs, USDA Agricultural Census and Soil Surveys), water district databases (especially those associated with nitrate studies or nitrate management plans), published nitrate models, and from the proposed denitrification studies previously described.

Proxy parameters would ideally be readily available in the existing Geotracker database or in databases that will eventually be incorporated into the Geotracker database. DWR data on well completion depth and aquifer lithology are potentially quite valuable. In the majority of field studies documenting denitrification, dissolved organic carbon is cited as the principal electron donor. Several authors, however, have emphasized the importance of solid phases in contributing to aquifer reducing capacity (Christensen et al., 2000, and references therein; McGuire et al., 2002). The reducing capacity of sediments should correlate with lithology, e.g. fine-grained marine and fluvial sediments are expected to contain more organic matter and reduced iron sulfide phases than coarse-grained alluvial sediment. Aquifers with higher proportions of clay may have proportionally more reducing capacity. This may be especially true on the longer time scales appropriate for deep drinking water aquifers. Nolan (2001) used percent organic matter in soils in combination with depth to the seasonally high water table to indicate conditions conducive to denitrification during infiltration. Depth to water table and screened interval are available from DWR, and soil parameters are available from USDA and/or California DPR. The Minnesota approach uses indices of groundwater oxidation state: $\mathrm{E}_{\mathrm{H}}$, $\mathrm{DO}$, and $\mathrm{Fe}^{2+}$. Water district records may include $\mathrm{E}_{\mathrm{H}}$ and $\mathrm{DO}$ for many of their public drinking water wells; iron data are already present in the Geotracker database.

An important aspect of this task would be to determine if available data are sufficient for estimating aquifer assimilative capacity. As an example, the presence or absence of iron may not be an appropriate proxy under certain conditions because aquifer sediments are iron poor, or because reduced ferrous iron has precipitated as solid sulfide phases (e.g., FeS or $\mathrm{FeCO}_{3}$ ). 


\section{Aquifer Assimilative Capacity Task 4: \\ Develop a saturated zone denitrification model for nitrate management planning and groundwater basin assessment}

Much effort has gone into developing detailed models and management plans for nitrogen in soil, manure, and fertilizer. These models generally predict nitrate flux ("leakage") out of the root zone. Evidence exists that denitrification does occur in the deep vadose and in the saturated zone. Developing a model for denitrification in the saturated zone below the root zone will be important in predicting future basin nitrate inventories, and in predicting response of the basin to changes in nitrate loading (resulting from different management plans or practices). Saturated zone transport models that incorporate denitrification do exist. Our ability to quantify denitrification progress and rate can be used to validate and refine existing models for use in basin assessment and management planning. 


\section{Improve Nitrate Source Attribution and Assess the Occurrence of Nitrate Co-contaminants}

Knowing the source of nitrate in a contaminated aquifer is critical for managing surface operations to prevent future contamination, and for evaluating exposure of human populations to nitrate co-contaminants. Source attribution can be addressed, at least in part, by monitoring the stable isotopic composition of the nitrogen and oxygen in nitrate dissolved in groundwater. In addition, detection in groundwater of nitrate co-contaminants that are specific to certain land uses (such as herbicides used in agriculture, or pathogens associated with confined animal operations) can also be valuable for source attribution. In addition to their relevance to source attribution, co-contaminants may pose human health risks beyond those posed by nitrate itself. The pervasiveness of nitrate-impacted waters in the State's drinking water supply increases the probability of low-level human exposure to contaminants that have the same source as anthropogenic nitrate (primarily agricultural operations, animal operations, or septic systems). Understanding the occurrence of these contaminants has implications for human health risk assessment (especially where synergistic effects are important) and for remediation (i.e., which treatment methods would be appropriate to address all contaminants). Since the occurrence of nitrate co-contaminants has not been adequately addressed to date, we propose measurement of potentially significant co-contaminants and assessment of their value for source attribution and human health risk evaluation

\section{Using stable isotope ratios ( $\delta^{15} \mathrm{~N}$ and $\delta^{18} \mathrm{O}$ ) for nitrate source attribution}

Kendall (1998) has reviewed the use of stable isotopes for nitrate source attribution and for demonstrating denitrification (Figure 9).Most terrestrial materials have $\delta^{15} \mathrm{~N}$ compositions between -20 and +30 per mil. Potential major sources of nitrate to groundwater include atmospheric deposition, decomposition of natural soil/sedimentary organic material, animal and septic waste, and fertilizer (produced from atmospheric nitrogen or from animal manure). While the ranges in $\delta^{15} \mathrm{~N}$ exhibited by these various sources are different, there is considerable overlap, especially for atmospheric, soil, and inorganic (atmospheric-derived) fertilizer sources ( -4 to +5 per mil). Manure and septic waste are usually distinguishable from other sources, with significantly "heavier" (more positive) $\delta^{15} \mathrm{~N}$ values (+10 to +20 per mil). Earlier source attribution studies that relied on nitrate- $\delta^{15} \mathrm{~N}$ alone, however, were often confounded by an inability to distinguish source signatures from the effects of isotopic fractionation associated with nitrogen cycling (Figure 8). As an example, an enriched nitrate- $\delta^{15} \mathrm{~N}$ composition may indicate a manure or septic source or may indicate extensive denitrification of a synthetic fertilizer source (see discussion of denitrification in previous section). 


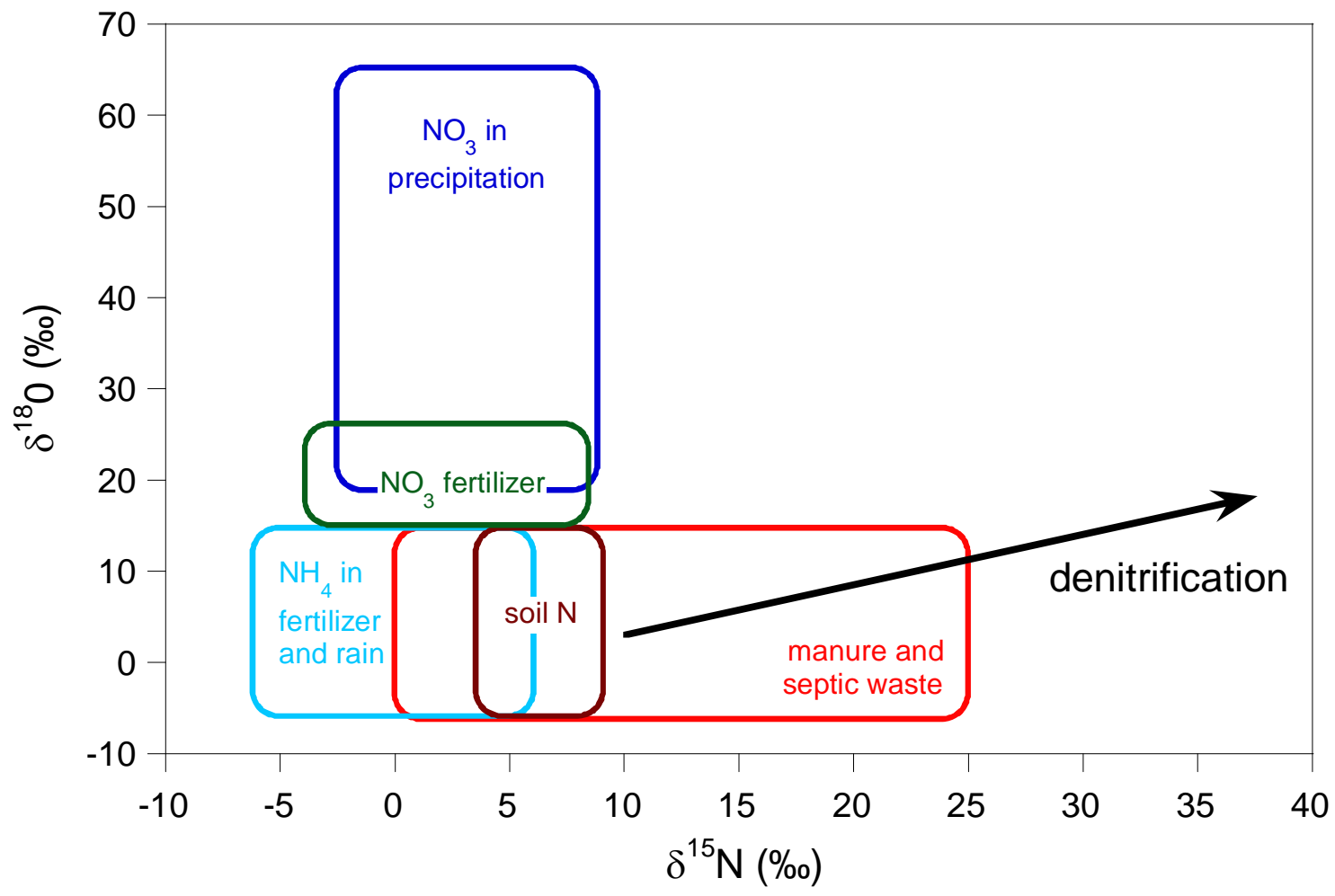

Figure 9: Isotopic composition of nitrogen and oxygen in nitrate from different sources (after Kendall, 1998).

The use of nitrate- $\delta^{18} \mathrm{O}$ gives additional information. Nitrate- $\delta^{18} \mathrm{O}$ values from different sources show considerable overlap, although nitrate in precipitation and in synthetic nitrate fertilizers is generally distinguished by its heavier (more positive) $\delta^{18} \mathrm{O}$ ( $>15$ per mil) as compared to soil, manure or septic sources ( $<10$ per mil). Recent studies, however, have demonstrated limitations in using nitrate- $\delta^{18} \mathrm{O}$ to distinguish natural from fertilizer sources of soil nitrate (Mengis et al., 2001). A more powerful application of nitrate- $\delta{ }^{18} \mathrm{O}$ data is in studies that attempt to distinguish septic and manure sources from fertilizer and natural sources. The ability to quantify the effects of denitrification on the isotopic composition of nitrate (see denitrification discussion) allows correction for these effects and an estimate of the original nitrate isotopic composition. With a dual isotope approach, nitrate- $\delta^{15} \mathrm{~N}$ becomes a much more robust tool for distinguishing fertilizer from septic sources of nitrate in groundwater.

In hydrogeologic settings where the goal is to distinguish between potential sources of nitrate to groundwater, and where confirming or ruling out a septic or manure source is of interest, analyzing for the stable isotopes of $\mathrm{N}$ and $\mathrm{O}$ in nitrate could provide conclusive evidence. The approach is limited, however, by uncertainties introduced from isotopic fractionations associated with nitrogen cycling (Mengis et al., 2001), and by the overlap in certain source signatures (e.g. septic systems and manure). For these reasons, the use of multiple tracers is an important tool in source attribution. As an example, a wastewater origin indicated by nitrate isotopic evidence can often be confirmed by analysis of a major cation such as $\mathrm{Na}^{+}$, and septic or municipal waste can 
be distinguished from animal waste by the occurrence of trace constituents such as EDTA or caffeine, or by the presence of high levels of boron with distinct isotopic composition (see for example Aravena and Robertson, 1998; Leenhouts et al., 1998).

\section{Nitrate Co-contaminants}

For groundwater contamination associated with agricultural operations, animal operations, or human waste disposal, nitrate may co-occur with other anthropogenic contaminants. Cocontamination with nitrate is an important factor in assessing risks associated with use of contaminated groundwater, and may influence decisions about managing the resource (e.g., whether to remediate the water, and if so, what treatment methods would be appropriate to address all contaminants).

In agricultural areas, possible co-contaminants with nitrate in groundwater include pesticides, herbicides, and their transformation products. In a recent national survey of organic contaminants and nitrate in groundwater, the U.S.G.S. reported triazine herbicides and their transformation products as among the most frequent co-contaminants with nitrate in the 1497 wells sampled (Squillace et al., 2002). The Department of Pesticide Regulation (California EPA, 2000b) has recently documented the contamination of California well water by pesticides/herbicides including the triazine herbicide simazine, the triazine-herbicide transformation products ACET (2-amino-4-chloro-6-ethylamino-s-triazine) and DACT (2, 4-diamino-6-chloro-s-triazine), the herbicide diuron, the herbicide norflurazon, and the pesticide DBCP (1,2-dibromo-3chloropropane), which was phased out in the early 1980s but is still detected in groundwater. The frequencies of detection of the transformation products ACET (76 detections/110 wells sampled, or $69 \%$ ) and DACT (69 detections/103 wells sampled, or 67\%) were more than 10 -fold greater than those of their potential parent compounds simazine or atrazine (up to 69 detections/1353 wells sampled, or 5.1\%) (California EPA, 2000b). In fact, degradation products of triazine herbicides have previously been reported to be more prevalent than their parent compounds in groundwater (Kolpin et al., 1996; Kolpin et al., 2001). Transformation products of pesticides/herbicides are seldom regulated and thus rarely subject to analysis in groundwater. However, they may be of concern if present in nitrate-contaminated water that is being considered for restoration and re-use.

As milk and beef production are respectively the number one and two agricultural industries in California (CDFA, 1989), potential nitrate co-contaminants from bovine operations are of statewide relevance. Potential co-contaminants include pathogenic bacteria (e.g., Escherichia coli O157:H7) and protozoa (e.g., Cryptosporidium and Giardia) (e.g., Gagliardi and Karns, 2000; Hooda et al., 2000; Kudva et al., 1998; Zhao et al., 1995). In addition, bovine enteroviruses have been suggested as fecal contaminants originating uniquely from animals such as cattle (Ley et al., 2002). Potential chemical co-contaminants from animal operations include antibiotics. We are not aware of any systematic assessments of these potential co-contaminants in groundwater near animal operations facilities in California.

Sources of human waste, such as septic systems, may be associated with nitrate co-contaminants that can be distinguished from bovine waste; thus, these co-contaminants could be particularly useful for source attribution. Caffeine is a unique indicator of human waste that has been widely detected in surface waters and groundwater, and its presence in environmental samples has specifically been linked to wastewater treatment plant effluent (Kolpin et al., 2002; Seiler et al., 1999 and references therein; Standley et al., 2000). Apparently, caffeine can be detected in the 
environment despite its relatively high biodegradability. Another potential co-contaminant with human waste sources is EDTA (ethylenediaminetetraacetic acid), a synthetic complexing agent that is widely used as a food additive/preservative and as an additive to household products, such as soaps and detergents. EDTA is relatively persistent and has been found in sewage effluents, surface water, and groundwater (Nowack et al., 1996). EDTA may be less unique to human waste than caffeine, as EDTA may be used in animal feed or other products associated with animal operations.

\section{Nitrate Source Attribution Specific Tasks}

The tasks described below are proposed to address nitrate co-contaminants associated with agricultural operations, animal operations, or human waste disposal. All tasks contribute to some degree to source attribution, whereas the second and fourth also address co-contaminants that may present human health risks.

\section{Nitrate Source Attribution Task 1:}

Evaluate the usefulness of nitrate co-contaminants for source attribution, susceptibility assessment, assessment of management practices, and remediation planning

Using data management and integration tools described in the section on Groundwater Basin Assessment, we can assess the utility of nitrate co-contaminants for a variety of water management applications. For regions of California that are rich in groundwater data on nitrate and the co-contaminants discussed above, spatial correlations between concentrations of nitrate and co-contaminants can be analyzed. Trends can be compared among regions with different land uses (e.g., areas with crop production vs. concentrated animal operations vs. human sewage input). Strong correlations in regions with specific land uses would suggest the utility of cocontaminants for nitrate source attribution. We can also assess the scale of correlations, that is, whether they are highly localized or more regional in scale. Modeling and assessment of aquifer susceptibility will benefit from knowledge of the scale of correlations, which will ultimately be a function of differential source loading as well as transport and fate properties of nitrate vs. the co-contaminants. In turn, more information on source attribution and aquifer susceptibility will provide better information for management practices and remediation planning.

Many of the nitrate co-contaminants discussed above are not regulated in groundwater and thus are not monitored throughout California. Nonetheless, these co-contaminants may be relevant because they can occur at relatively high frequencies in groundwater and/or potentially pose health risks. Therefore, to assess their usefulness, it will be necessary to generate additional data for these co-contaminants in strategically selected regions representing specific land uses. Generation of additional co-contaminant data is discussed below.

\section{Nitrate Source Attribution Task 2: \\ Develop and use analytical techniques to document the occurrence of prevalent herbicides and their transformation products in nitrate-contaminated California groundwater}

To better understand the distributions of herbicide-related co-contaminants in nitratecontaminated groundwater, we can augment data available from California agencies. A recent DPR report (California EPA, 2000b) suggests that approximately 110 wells are tested for simazine and the related transformation products ACET and DACT; most of these wells are 
located in Fresno and Tulare counties. If the geographic distribution of these wells is not sufficient to allow for detailed analyses of correlations between these compounds and nitrate, we can develop rapid, sensitive, and specific analyses for these compounds in groundwater and generate additional data for strategically selected regions. Similarly, analyses can be developed for diuron, norflurazon, and their dominant transformation products such as N-(3,4dichlorophenyl)-N-methylurea (from diuron, Field et al., 1997) and demethylnorflurazon (Coupe and Thurman, 2002)\}. Apparently, no data exist for transformation products of diuron and norflurazon in California groundwater.

Standard analytical methods promulgated by regulatory agencies (such as U.S. EPA) do not exist for the transformation products discussed in the preceding paragraph because these compounds are not regulated. To maximize efficiency, we can develop analytical methods that will measure the parent herbicides and their transformation products in a single analysis. Analytical method development would build on published methods to the extent possible and will focus on solidphase extraction (SPE) and liquid chromatography/tandem mass spectrometry (LC/MS/MS), which is a very sensitive and specific technique for the compounds of interest. Analytical chemists at LLNL have successfully developed rapid, sensitive, and reliable methods for LC/MS/MS analysis of environmental contaminants and their transformation products in groundwater (e.g., Beller, 2002; Beller and Tiemeier, 2002).

Nitrate Source Attribution Task 3:

Develop and use analytical techniques to document the occurrence of human waste cocontaminants in nitrate-contaminated California groundwater

Caffeine and EDTA can be analyzed in groundwater samples from strategically selected areas using SPE-LC/MS/MS. Using these techniques, sensitivity should be sufficient to detect these compounds at the ng/L concentrations that will probably apply to groundwater. These tracers will be used in conjunction with oxygen and nitrogen isotope ratios (Abbas and Mostafa, 2000). EDTA, in particular, is expected to behave relatively conservatively during infiltration and transport.

\section{Nitrate Source Attribution Task 4:}

Develop and use analytical techniques to document the occurrence of bacterial and viral co-contaminants in nitrate-contaminated California groundwater

Dairy farms and other animal operations could result in the transport of viruses or pathogenic bacteria into nearby groundwater. As is the case for herbicides and their transformation products, these microbial co-contaminants could be an important factor in assessing risks associated with use of nitrate-contaminated groundwater and may influence decisions about managing the resource. Since no systematic data have been generated for these microbes in groundwater, we would analyze samples in strategically selected areas to investigate correlations between nitrate concentrations and specific bacterial or viral populations.

LLNL has extensive experience in rapid and specific detection of microorganisms (including pathogenic bacteria) using a variety of methods. For determination of Escherichia coli O157:H7 in groundwater, a rapid and highly specific method based on real-time Polymerase Chain Reaction (PCR) could readily be adapted from existing methods designed for other matrices (Ibekwe et al., 2002). LLNL scientists have extensive experience in detecting specific bacteria or 
bacterial genes in complex environmental matrices, such as soil or aquifer sediment (e.g., Beller et al., 2002). For analysis of bovine enteroviruses, reverse transcription PCR would be appropriate (e.g., Ley et al., 2002), since these are RNA viruses. 


\section{Assess the Effect on Nitrate Management Plans and Best Management Practices on Groundwater}

The State Water Resources Quality Control Board is responsible for protecting California's groundwater resources from degradation. Remediation of waters that exceed the MCL for nitrate is expensive. A far more cost-effective approach is to manage source loading to prevent groundwater nitrate levels from exceeding drinking water standards, with priority given to those basins that have elevated levels of nitrate and are currently receiving significant fixed nitrogen input. California, to a large extent, has adopted a non-regulatory approach with heavy reliance on developing and encouraging adoption of best management practices for fertilization and animal operations. A number of water districts, with state (SWRCB) and federal (U.S. EPA) assistance, have instituted Nitrate Management Plans, which often involve public outreach and education. On a larger scale, the CDFA Fertilizer Research and Education Program has been conducting research into Best Management Practices for control of nitrate leaching, and has been interacting with the agricultural community for more than 10 years.

Quantifying the effect of nitrate management practices on groundwater nitrate is difficult and can rarely be accomplished by simple time-series concentration data, especially over short time scales in deep drinking-water supply aquifers. This is because of the complexity and time scale of nitrate loss from the soil horizon, transport through the deep vadose zone, and mixing, transport, and denitrification in unconfined and confined aquifers, and because land use has changed in many parts of California over the past several decades. For water district plans, the problem is especially severe - funding for such efforts is generally 2-3 years and rarely allows follow-on studies of plan impact. Long-term assessment of land use and nitrate management practices on deep basins is a key gap in the current approach to nitrate contamination.

\section{Agricultural management practices}

Demonstrating the effectiveness of specific nutrient management practices is important in gaining acceptance by the agricultural community. Although many of the best management practices result in a net savings to farmers because of more efficient use of fertilizer, others involve more expensive forms of fertilizer (e.g. time-release forms) or initial investment in monitoring or irrigation systems. Manure management best practices often involve significant investment (for lining ponds, installing digesters, etc). If the agricultural community does not change management practices to reduce source loading, loss of potable groundwater to nitrate contamination may force the State to explore alternatives. One alternative is remediation. A technology to inexpensively remove nitrate and nitrate co-contaminants from groundwater (at the wellhead, for example) is not now available, and may not be effective against nitrate cocontaminants. Remediation is important, nevertheless, in an integrated approach to nitrate management.

Another alternative to voluntary acceptance of best management practices is regulation. Arizona, for example, places general restrictions on nutrient runoff. The State of Arizona grants farmers a general permit for nitrogen fertilizer application that requires nitrogen best management practices (BMPs). If the State finds that a farmer is not using BMPs, it will revoke the general permit and require an individual permit (USDA, 1997). An individual permit is more difficult to obtain and invokes severe monetary penalties for farmers in violation. The adoption of this 
approach for irrigated agriculture in California would be exceptionally difficult, and perhaps impossible, without demonstrating the effectiveness of nutrient management.

For confined animal feeding operations (CAFOs), the Federal government is moving toward a regulatory approach. In 1999, the USDA and EPA released the Unified National Strategy for Animal Feeding Operations. The Unified Strategy sets forth a framework of actions that USDA and EPA plan to take under existing and legal and regulatory authority to reduce water quality and public health impacts from improperly managed animal wastes. Under the Strategy, both confined and unconfined animal operations would voluntarily implement Comprehensive Nutrient Management Plans (CNMPs) with USDA guidance. CAFOs, which are considered point sources of pollutions and are subject to USEPA National Pollutant Elimination System (NPDES) permitting, would be required to implement both a CNMP and a Permit Nutrient Plan. PNPs are site-specific plans that describe how the operator intends to meet the effluent discharge limitations and other requirements of the NPDES permit. Degradation of surface water is the regulatory driver in NPDES permitting. The development of CMNPs, however, takes into account nutrient loading on subsurface waters. Understanding aquifer assimilative capacity and demonstrating the effect of different plans will be important in setting CNMP guidelines for nondegradation of subsurface drinking water supplies.

\section{Water management practices: Artificial recharge}

The State Board also needs a tool for predicting the effects of different water management practices on subsurface water quality. For example, in artificial recharge facilities, source water nitrate may be converted to nitrogen by denitrification in recharge basin sediment or in the saturated zone. Dilution with ambient groundwater or with natural recharge is also likely to occur. Proposed DHS regulations for recharge of wastewater for subsequent potable use require $50 \%$ dilution with water of non-wastewater origin, and a maximum of $3 \mathrm{mg} / \mathrm{L}$ nitrate- $\mathrm{N}$ in the blended water. In these situations, a monitoring effort that depended upon dilution for compliance would need to be much more extensive than one where denitrification is demonstrated with the caveat that monitoring of a denitrification system would require demonstration that denitrification was indeed occurring.

The distinction between dilution and denitrification is also crucial information for predicting what will happen if there is a large fluctuation in the water table, as takes place during drought conditions, or during episodic artificial recharge. A shallow nitrate source that is perched during low water table conditions could contribute significantly when the level of the water table rises. A combination of groundwater age data that delineates the flow field around artificial recharge bodies, and geochemical data related to nitrate occurrence and denitrification, could help identify areas poorly suited for artificial recharge. In contrast, geochemical analyses can used to identify areas where denitrification during artificial recharge is most likely to occur, resulting in improved water quality. In summary, a detailed understanding nitrogen cycling during recharge will (1) provide input to DHS on allowable levels of nitrate in source waters, and (2) allow recharge systems to be designed that enhance denitrification. 


\section{Remediation and denitrification}

A significant factor in the intractability of nitrate contamination is the cost of removing nitrate from large volumes of water. Requisite targets for nitrate removal include contaminated groundwater, municipal wastewater, blended waters to be used for groundwater recharge, irrigation drainage waters, and discharge from animal operations. Treatment can occur in water treatment facilities, at the well-head, in the soil zone or in-situ. This is an extremely active area of research. Efficient technologies currently exist for removing nitrate from large volumes of water above ground and from small volumes of water in the subsurface - the issues are cost, throughput, and disposal of waste produced during treatment.

Microbiological denitrification can be engineered ex situ or in-situ to remove nitrate from a contaminated groundwater, wastewater, or recharge water. The use of biological denitrification in wastewater treatment has been studied extensively (Grady et al., 1999), and its application to drinking water treatment is gaining acceptance (Fuchs et al., 1997; Mekonen et al., 2001). One advantage over nitrate removal systems that do not convert nitrate to nitrogen (e.g. ion exchange or reverse osmosis) is that a nitrate waste stream is not produced. A second advantage is that denitrification is applicable to in-situ and soil/sediment applications. The disadvantage of such denitrification systems is the limited ability to process large volumes of water.

In the context of contaminated aquifer cleanup, denitrification can be used as the treatment portion of a traditional "pump-and -treat" system. Extracted groundwater is amended with a suitable electron donor (e.g. acetate from food-grade vinegar) and passed through a biological reactor containing denitrifying organisms, which respire the nitrate to nitrogen gas, a benign endproduct.

More recently, in-situ treatment of nitrate contaminated groundwaters has been investigated (ITRC, 2000; Kapoor and Viraraghavan, 1997). In this approach, microbial denitrification is promoted within the contaminated aquifer itself by addition of an electron donor. Advantages include potential savings in cleanup time and cost, as compared to traditional pump-and-treat systems, and potential savings of water resources, as compared to pumping and discharging water above ground. Disadvantages include difficulty in monitoring system performance, and in the case of biological processes, biofouling of wells and possible deterioration of water quality (especially if the water also contains sulfate). The ability to confirm and quantify denitrification during monitoring is essential to the acceptance of this approach.

A third application of microbial denitrification is in the design, construction and maintenance of surface recharge facilities. Recharge ponds that are not frequently scraped may be modeled as wetlands, for which a large denitrification literature exists (e.g. Bachand and Horne, 2000; Reilly et al., 2000). As discussed above, a detailed understanding of nitrogen cycling in these systems, and monitoring to demonstrate that denitrification is occurring during recharge have become increasingly important with the increasing needs for storage capacity and with the potential for stringent regulation on nitrate levels in recharging water.

\section{Specific Tasks for Nitrate Management Plan Assessment}

Age-dating, source attribution and characterizing denitrification in the recharge and saturated zones can all contribute to a more robust assessment of the effect of nutrient and water management practices on groundwater nitrate levels. 


\section{Nitrate Management Plan Assessment Task 1: Use CAS groundwater ages to demonstrate the relationship between land use and groundwater nitrate}

Age-dating young groundwater is a powerful tool in assessing how changes in land use and agricultural management practices affect groundwater nitrate concentrations. Examples of the types of changes that could potentially affect groundwater nitrate concentrations include land use (e.g. residential development on agricultural land), agricultural management practices (e.g. nutrient management plans for confined animal feeding operations and best management practices for fertilizer application), recharge (e.g. installation of artificial recharge facilities or cessation of stream recharge), and drainage and irrigation (e.g. installation of tile drains or changes in irrigation method and timing). Since both land use and agriculture have changed significantly in California over the last few decades, being able to age date a parcel of groundwater is critical to attributing a specific groundwater nitrate concentration to a specific land use or management practice, and to estimating the time scale over which changes in management practices will affect groundwater quality.

In this regard, the CAS dataset is extremely valuable in that it includes water mass time markers. A cursory evaluation of CAS results and nitrate occurrence in drinking water wells shows that a slight expansion and further 'mining' of the CAS data set may be valuable in assessing how changes in surface loading affect groundwater nitrate concentrations.

- In the Orange County Basin, high nitrate in drinking water wells occurs almost exclusively in the forebay, and not in the 'pressure zone', in keeping with results for lowlevel VOCs measured for CAS (Figure 10). However, young groundwaters close to the artificial recharge ponds do not contain high levels of nitrate. Nitrate occurrence is most widespread in the downgradient area of the forebay, where mean groundwater ages are 20 to 35 years. Thus, a nitrate 'front' associated with past land use practices may be present in the distal portions of the forebay. Interestingly, two areas where VOCs occur in 'premodern' or 'tritium-dead' water (in Fullerton and Tustin) are also areas of concern for nitrate. Such "short-circuit" represent contamination pathways that may be important in assessing the susceptibility of deep, old groundwater to nitrate contamination.

- Santa Clara Valley has more than 50 drinking water wells (some inactive) with reported nitrate levels above the MCL. A temporal trend analysis carried out by SCVWD shows a band of wells with upward trending nitrate concentrations in an arc that parallels SF Bay near the northern boundary of the basin. Further south, many wells show downward trends in nitrate. The observed pattern in tritium concentration from the CAS study suggests that in the older water (with a small post-modern component) increasing nitrate is observed, while younger water is more likely to have decreasing nitrate concentrations. Land use has changed significantly in Santa Clara Valley over the past several decades, as has groundwater management. 


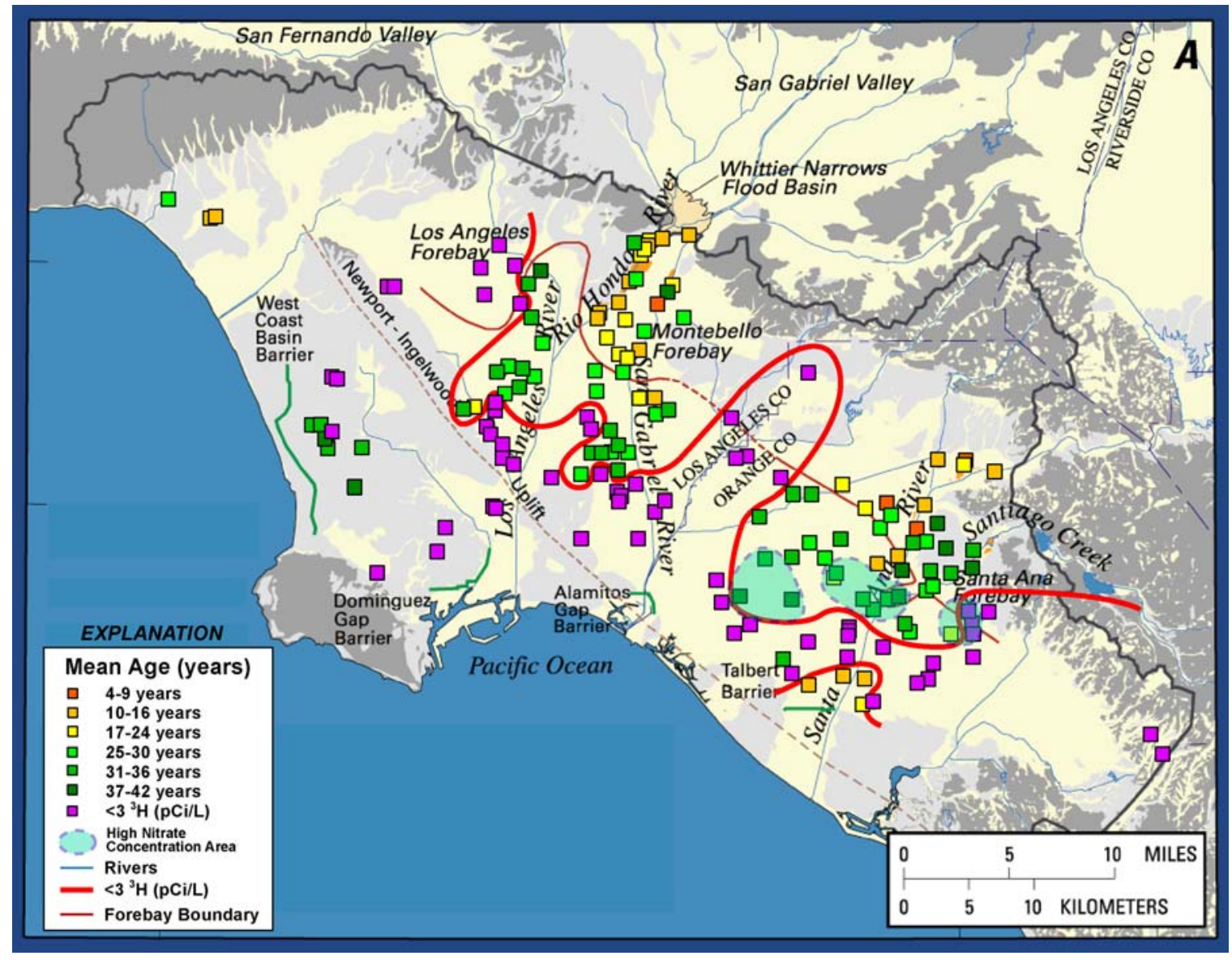

Figure 10. Groundwater ages and nitrate contamination in the Orange County and Los Angeles Basins (CAS data. Groundwater ages were determined using the tritium-helium method in support of the GAMA CAS program. Note that nitrate contamination is most intense in older forebay water, and not in tritium-dead pressure-zone water.

A more detailed analysis of CAS data where land use or nitrate management has changed significantly in the past may produce valuable insights into the effect and timescale of surface management on groundwater resources. Data analysis will also reveal where data gaps exist and need to be supplements by additional field surveys or monitoring.

\section{Nitrate Management Plan Assessment Task 2:}

Perform focused field studies to demonstrate the utility of an integrated approach to groundwater nitrate characterization in nitrate assessment and management

Field studies utilizing age-dating, source attribution, and denitrification characterization are a powerful approach to designing appropriate nitrate management plans and to assessing the effectiveness of nitrate management plans. Four targets for focused field studies include characterization of existing nitrate plumes to determine their source, history, and future in support of nitrate management planning; evaluation of temporal changes in nitrate along a 
groundwater flowpath; coupling of basin-scale groundwater nitrate characterization to field-scale studies of nitrate leaching in agricultural settings; and evaluation of denitrification during artificial or enhanced surface recharge. Focused field studies offer the opportunity to gather the data necessary to develop useful nitrate management and basin assessment models and to determine the limitation of these models in data-sparse environments

\section{Nitrate plume characterization}

A number of potential sites exist for pilot studies to demonstrate the value of this approach. The source, age and denitrification status of the Buena Vista plume in the Livermore-Amador basin is not known, making design of an effective management plan difficult. A mixed septic and livestock source is suspected (Zone 7 Water Agency, 2002). The replacement of septic systems with sewers would require convincing evidence that septic discharge in the unincorporated Buena Vista Road area is the primary source and is ongoing. Groundwater age, total flux of anthropogenic nitrate to the plume (including loss from denitrification), and source attribution could provide an answer. Zone 7 is interested in working with LLNL on this problem. Being able to distinguish septic system sources from livestock or natural sources is an issue in several communities, especially those in the Sierra foothills (e.g. Chico).

\section{Temporal changes in nitrate along groundwater flow paths}

Evaluating temporal changes in dissolved nitrate along a groundwater flowpath would involve not only documenting such change but constraining the cause of the trend (e.g. is it due to dispersion or mixing, denitrification, or source-loading). Flowpath studies could be conducted in basins with active nitrate management plans to assess the success of those plans, or in basins where land use has changed significantly to evaluate the effect of land use on nitrate loading in support of groundwater basin assessment. Such studies will be most effective when conducted at wells with small, discrete screened intervals, so that a narrow range in groundwater age is sampled.

The apparent age trends in nitrate contaminated groundwaters in northern Santa Clara Valley have been discussed. For this area, supplementing the CAS data set with nitrate-specific studies of source and geochemistry would provide a clear example of how changes in land use affect groundwater nitrate. In southern Santa Clara Valley, nitrate contamination in shallow groundwaters of the Llagas subbasin has affected domestic drinking water wells and led to the development and implementation of a nitrate management plan (SCVWD, 1994; SCVWD, 1996). Resampling of these wells would allow assessment of the success of the program. The Santa Clara Valley Water District is interested in working with LLNL on these issues.

\section{Agricultural field studies}

For evaluation of the effect of changes in agricultural practices on groundwater nitrate, we have access to long-term study sites maintained by Dr. Thomas Harter of the UC-Davis Agricultural Extension Service. The goal of Dr. Harter's studies is to determine the effect of nutrient management on shallow groundwater immediately underlying agricultural operations. The effects on downgradient and deeper groundwaters have not been examined, and these sites will offer an opportunity to demonstrate the effect of agricultural practices on groundwater at a scale of interest for basin assessment. Of particular importance is the input of ammonia-N and oxygen demand to shallow groundwaters. These sites provide an opportunity to link field-scale processbased solute transport models that predict nitrate leaching out the soil zone to basin-scale property-based index models that predict groundwater vulnerability to nitrate contamination. 


\section{Artificial recharge field studies}

For studies of groundwater recharge, the Alameda County Water District ponds in Fremont and the Orange County Water District ponds in the forebay offer endmember examples of surface recharge facility management - the OCWD ponds are scraped every year, whereas the ACWD ponds are scraped infrequently. Pond sediment may be a locus for denitrification, and nitrateloading in recharge waters may be significantly different immediately before and after scraping. Evaluation of the source, direction of movement, and rate of movement of nitrate from artificial recharge facilities using CAS, stable isotope, and nitrate data should allow delineation of locations where denitrification is likely to take place during artificial recharge. LLNL has a working relationship with both districts.

\section{Nitrate Management Plan Assessment Task 3: Critically review available and emerging nitrate remediation technologies and assess their cost, applicability and limitations in the context of California water and energy}

Nitrate remediation of large volumes of water is costly but may become increasingly necessary as demand for drinking water in California increases. Orange County Water District's Tustin water treatment facility and Prado wetlands are two large projects necessitated by the need for nitrate removal. A number of factors are involved in the feasibility of nitrate remediation, and in predicting the role of remediation in California's approach to pervasive nitrate contamination. Treatment is primarily an economic decision and balances the cost of treatment against the cost of developing new water supplies. Factors that must be considered include cost (both initial and operational), dependence on reliable energy supply, disposal of produced waste streams, and required throughput. The composition of the water to be treated is an important parameter. If cocontaminants are present, their removal needs to be considered. If high levels of bromine or natural organic matter are present, systems involving disinfection by chlorination (to prevent biofouling of reverse osmosis membranes for example) may produce disinfection byproducts (DBPs) at unacceptable levels. Finally, if new supplies of uncontaminated water (e.g. from drilling new wells) are available for some time in the future and if contamination of those supplies can be prevented or mitigated through an effective management plan, waiting for the development of new inexpensive technologies to remove nitrate may be feasible.

LLNL has experience in the design and operation of a number of above ground denitrification systems. One version consists of containerized wetland that promotes both microbiological denitrification and plant uptake of nitrate, and has been applied in remote locations for the treatment of low flows of contaminated groundwater (Krauter and Daily, 1999). A second version utilizes microbiological denitrification in a closed reactor for treatment of higher volumes of contaminated groundwater (Krauter, 2001). A third version consists of an opencontainer bio-reactor for wellhead treatment (Daily et al., 2001). LLNL is also developing smart membrane and electrochemical methods for removing salts from water, and is testing enhanced granular activated carbon (GAC) formulations for removal of uranium and arsenic (which are both anions in groundwater as is nitrate). The addition of small amounts of functionalized aerogel (a high surface area material developed at LLNL) to GAC produces a contaminantspecific sorbent that can be used with the existing water treatment infrastructure in the developed and developing world. If the material can be produced cheaply enough, wellhead treatment would be feasible. 
LLNL has expertise in both technology development and in economic decision making (e.g. the CALVIN water distribution model). With this expertise, LLNL could produce a critical review of current and emerging nitrate remediation technologies. Such a review would include an appraisal of current remediation projects in California, a review of current research in new remediation technologies, and a framework for decision making that could be used by water districts or vendors. 


\section{References}

Abbas M. N. and Mostafa G. A. (2000) Determination of traces of nitrite and nitrate in water by solid phase spectrophotometry. Analytica Chimica Acta 410(1-2), 185-192.

Anton E. C., Barnickol J. L., and Schnaible D. R. (1988) Nitrate in Drinking Water: Report to the Legislature, Division of Water Quality Report No. 88-11WQ, California State Water Resources Control Board.

Aravena R. and Robertson W. D. (1998) Use of multiple isotope tracers to evaluate denitrification in ground water: Study of nitrate from a large-flux septic system plume. Ground Water 36(6), 975-982.

Avery A. A. (2001) Cause of methemoglobinemia: Illness versus nitrate exposure. Environmental Health Perspectives 109(1), A12-A13.

Bachand P. A. M. and Horne A. J. (2000) Denitrification in constructed free-water surface wetlands: I. Very high nitrate removal rates in a macrocosm study. Ecological Engineering 14(1-2), 9-15.

Beam S. (2002) Telephone conversation (ed. B. K. Esser).

Beller H. R. (2002) Analysis of benzylsuccinates in groundwater by liquid chromatography/tandem mass spectrometry and its use for monitoring in situ BTEX biodegradation. Environmental Science \& Technology 36(12), 2724-2728.

Beller H. R., Kane S. R., Legler T. C., and Alvarez P. J. J. (2002) A real-time polymerase chain reaction method for monitoring anaerobic, hydrocarbon-degrading bacteria based on a catabolic gene. Environmental Science \& Technology 36, 3977-3984.

Beller H. R. and Tiemeier K. (2002) Use of liquid chromatography/tandem mass spectrometry to detect distinctive indicators of in situ RDX transformation in contaminated groundwater. Environmental Science \& Technology 36(9), 2060-2066.

Böttcher J., Strebel O., Voerkelius S., and Schmidt H. L. (1990) Using isotope fractionation of nitrate nitrogen and nitrate oxygen for evaluation of microbial denitrification in a sandy aquifer. Journal of Hydrology 114(3-4), 413-424.

California DHS. (2002) Draft Recharge Regulations (Title 22, California Code of Regulations; Division 4,. Environmental Health; Chapter 3. Recycling Criteria), Department of Health Services.

California EPA. (1997) Nitrate and nitrite in drinking water California Public Health Goal (PHG), Office of Environmental Health Hazard Assessment.

California EPA. (2000a) Plan for implementing a comprehensive program for monitoring ambient surface and groundwater quality, State Water Resources Control Board.

California EPA. (2000b) Sampling for Pesticide Residues in California Well Water: 2000 Update of the Well Inventory Database, EH00-15, Department of Pesticide Regulation.

California State Auditor. (1998) California drinking water: State and local agencies need to provide leadership to address contamination of groundwater by gasoline components and additives.

CDFA. (1989) Nitrate and California Agriculture, California Department of Food and Agriculture. 
Christensen T. H., Bjerg P. L., Banwart S. A., Jakobsen R., Heron G., and Albrechtsen H. J. (2000) Characterization of redox conditions in groundwater contaminant plumes. Journal of Contaminant Hydrology 45(3-4), 165-241.

Corwin D. L., Vaughan P. J., and Loague K. (1997) Monitoring nonpoint source pollutants in the vadose zone with GIS (Review). Environmental Science \& Technology 31(8), 2157-2175.

Coupe R. H. and Thurman E. M. (2002) Herbicides and their metabolites in the surface waters of the Mississippi River alluvial plain., U.S. Geological Survey, http://wwwmswater.usgs.gov/nawqa/pubs/posters/herbs_metabs/herbs_and_metabolites.h $\underline{\mathrm{tm}}$.

Daily W. D., Halden R. U., and Krauter P. W. (2001) Removal of nitrate from groundwater using open container bio-reactors (abstr.). Sixth International Symposium on In Situ and OnSite Bioremediation (San Diego, June 4-7, 2001), Lawrence Livermore National Laboratory UCRL-PRES-143762, 1 p.

Desimone L. A. and Howes B. L. (1996) Denitrification and nitrogen transport in a coastal aquifer receiving wastewater discharge. Environmental Science \& Technology 30(4), 1152-1162.

Fan A. M. and Steinberg V. E. (1996) Health implications of nitrate and nitrite in drinking water - an update on methemoglobinemia occurrence and reproductive and developmental toxicity. Regulatory Toxicology and Pharmacology 23(1), 35-43.

Fan A. M., Willhite C. C., and Book S. A. (1987) Evaluation of the nitrate drinking water standard with reference to infant methemoglobinemia wand potential reproductive toxicity. Regulatory Toxicity and Pharmacology 7, 135-148.

Field J. A., Reed R. L., Sawyer T. E., and Martinez M. (1997) Diuron and its metabolites in surface water and ground water by solid phase extraction and in-vial elution. Journal of Agricultural and Food Chemistry 45(10), 3897-3902.

Fuchs W., Schatzmayr G., and Braun R. (1997) Nitrate removal from drinking water using a membrane-fixed biofilm reactor. Applied Microbiology and Biotechnology 48(2), 267274.

Gagliardi J. V. and Karns J. S. (2000) Leaching of Escherichia coli O157 : H7 in diverse soils under various agricultural management practices. Applied and Environmental Microbiology 66(3), 877-883.

Grady C. P. L. G., Daigger G. T., and Lim H. C. (1999) Biological Wastewater Treatment. Marcel Dekker.

Helperin A. N., Beckman D. S., and Inwood D. (2001) California's Contaminated Groundwater: Is the State Minding the Store?, Natural Resources Defense Council.

Hooda P. S., Edwards A. C., Anderson H. A., and Miller A. (2000) A review of water quality concerns in livestock farming areas. Science of the Total Environment 250(1-3), 143-167.

Ibekwe A. M., Watt P. M., Grieve C. M., Sharma V. K., and Lyons S. R. (2002) Multiplex fluorogenic real-time PCR for detection and quantification of Escherichia coli O157:H7 in dairy wastewater wetlands. Applied and Environmental Microbiology 68(10), 48534862. 
ITRC. (2000) Emerging Technologies for Enhanced In Situ Biodenitrification (EISBD) of Nitrate-Contaminated Ground Water, Interstate Technology and Regulatory Cooperation Group.

Kana T. M., Darkangelo C., Hunt M. D., Oldham J. B., Bennett G. E., and Cornwell J. C. (1994) Membrane inlet mass spectrometer for rapid high precision determination of N2, O2, and Ar in environmental water samples. Analytical Chemistry 66(23), 4166-4170.

Kapoor A. and Viraraghavan T. (1997) Nitrate removal from drinking water - Review. Journal of Environmental Engineering-ASCE 123(4), 371-380.

Kellogg R. L., Lander C. H., Moffitt D. C., and Geollehon N. (2000) Manure Nutrients Relative to the Capacity of Cropland and Pastureland to Assimilate Nutrients: Spatial and Temporal Trends for the United States, USDA Natural Resources Conservation Service.

Kendall C. (1998) Tracing nitrogen sources and cycling in catchments. In Isotope Tracers in Catchment Hydrology (ed. C. Kendall and J. J. McDonnell), pp. 519-576. Elsevier.

Kendall C. and McDonnell J. J. (1998) Isotope tracers in catchment hydrology. Elsevier.

Kölle W. O., Strebel O., and Böttcher J. (1985) Water Supply 3, 35-40.

Kolpin D. W., Furlong E. T., Meyer M. T., Thurman E. M., Zaugg S. D., Barber L. B., and Buxton H. T. (2002) Pharmaceuticals, hormones, and other organic wastewater contaminants in US streams, 1999-2000: A national reconnaissance. Environmental Science \& Technology 36(6), 1202-1211.

Kolpin D. W., Thurman E. M., and Goolsby D. A. (1996) Occurrence of selected pesticides and their metabolites in near-surface aquifers of the midwestern United States. Environmental Science \& Technology 30(1), 335-340.

Kolpin D. W., Thurman E. M., and Linhart S. M. (2001) Occurrence of cyanazine compounds in groundwater: Degradates more prevalent than the parent compound. Environmental Science \& Technology 35(6), 1217-1222.

Korom S. F. (1992) Natural denitrification in the saturated zone - a review. Water Resources Research 28(6), 1657-1668.

Krauter P. W. (2001) Using a wetland bioreactor to remediate ground water contaminated with perchlorate and nitrate. International Journal of Phytoremediation 3(3), 415-433.

Krauter P. W. and Daily W., Jr. (1999) Removing nitrate and perchlorate from ground water using the containerized wetland system, UCRL-MI-135903, Lawrence Livermore National Laboratory.

Kudva I. T., Blanch K., and Hovde C. J. (1998) Analysis of Escherichia coli 0157:H7 survival in ovine or bovine manure and manure slurry. Applied and Environmental Microbiology 64(9), 3166-3174.

Leenhouts J. M., Bassett R. L., and Maddock T. (1998) Utilization of intrinsic boron isotopes as co-migrating tracers for identifying potential nitrate contamination sources. Ground Water 36(2), 240-250.

Ley V., Higgins J., and Fayer R. (2002) Bovine enteroviruses as indicators of fecal contamination. Applied and Environmental Microbiology 68(7), 3455-3461.

Lichtenberg E. and Shapiro L. K. (1997) Agriculture and nitrate concentrations in Maryland community water system wells. Journal of Environmental Quality 26(1), 145-153. 
Loague K., Corwin D. L., and Ellsworth T. R. (1998) The challenge of predicting nonpoint source pollution. Environmental Science \& Technology 32(5), A130-A133.

Lovley D. R. and Chapelle F. H. (1995) Deep subsurface microbial processes. Reviews in Geophysics 33(3), 365-381.

Mariotti A., Landreau A., and Simon B. (1988) ${ }^{15} \mathrm{~N}$ isotope biogeochemistry and natural denitrification process in groundwater: Application to the chalk aquifer of northern France. Geochimica et Cosmochimica Acta 52, 1869-1878.

Marks R. (2001) Cesspools of Shame: How Factory Farm Lagoons and Sprayfields Threaten Environmental and Public Health, Natural Resources Defense Council.

McGuire J. T., Long D. T., Klug M. J., Haack S. K., and Hyndman D. W. (2002) Evaluating behavior of oxygen, nitrate, and sulfate during recharge and quantifying reduction rates in a contaminated aquifer. Environmental Science \& Technology 36(12), 2693-2700.

Mekonen A., Kumar P., and Kumar A. (2001) Use of sequencing batch reactor for biological denitrification of high nitrate-containing water. Journal of Environmental EngineeringAsce 127(3), 273-278.

Mengis M., Walther U., Bernasconi S. M., and Wehrli B. (2001) Limitations of using delta O-18 for the source identification of nitrate in agricultural soils. Environmental Science \& Technology 35(9), 1840-1844.

Moran J. E., Hudson G. B., Eaton G. F., and Leif R. (2002) A contamination vulnerability assessment for the Livermore-Amador and Niles Cone groundwater basins: Report to the California State Water Resources Control Board, UCRL-AR-148831, Lawrence Livermore National Laboratory.

Mueller D. K. and Helsel D. R. (1996) Nutrients in the Nation's Waters - Too Much of a Good Thing, Circular 1136, U.S. Geological Survey.

Nolan B. T. (1999) Nitrate behavior in ground waters of the southeastern USA. Journal of Environmental Quality 28(5), 1518-1527.

Nolan B. T. (2001) Relating nitrogen sources and aquifer susceptibility to nitrate in shallow ground waters of the United States. Ground Water 39(2), 290-299.

Nolan B. T., Hitt K. J., and Ruddy B. C. (2002) Probability of nitrate contamination of recently recharged groundwaters in the conterminous United States. Environmental Science \& Technology 36(10), 2138-2145.

Nolan B. T., Ruddy B. C., Hitt K. J., and Helsel D. R. (1997) Risk of nitrate in groundwaters of the United States - A national perspective. Environmental Science \& Technology 31(8), 2229-2236.

Nolan B. T. and Stoner J. D. (2000) Nutrients in groundwaters of the conterminous United States 1992-1995. Environmental Science \& Technology 34(7), 1156-1165.

Nowack B., Kari F. G., Hilger S. U., and Sigg L. (1996) Determination of dissolved and adsorbed EDTA species in water and sediments by HPLC. Analytical Chemistry 68(3), 561-566.

NRC. (1995) Nitrate and nitrite in drinking water, National Research Council.

Panno S. V., Hackley K. C., Hwang H. H., and Kelly W. R. (2001) Determination of the sources of nitrate contamination in karst springs using isotopic and chemical indicators. Chemical Geology 179(1-4), 113-128.

Page 60 of 62 
Pauwels H., Kloppmann W., Foucher J. C., Martelat A., and Fritsche V. (1998) Field tracer test for denitrification in a pyrite-bearing schist aquifer. Applied Geochemistry 13(6), 767778.

Postma D., Boesen C., Kristiansen H., and Larsen F. (1991) Nitrate reduction in an unconfined sandy aquifer - water chemistry, reduction processes, and geochemical modeling. Water Resources Research 27(8), 2027-2045.

Puckett L. J. and Cowdery T. K. (2002) Transport and fate of nitrate in a glacial outwash aquifer in relation to ground water age, land use practices, and redox processes. Journal of Environmental Quality 31(3), 782-796.

Puckett L. J., Cowdery T. K., Lorenz D. L., and Stoner J. D. (1999) Estimation of nitrate contamination of an agro-ecosystem outwash aquifer using a nitrogen mass-balance budget. Journal of Environmental Quality 28(6), 2015-2025.

Reilly J. F., Horne A. J., and Miller C. D. (2000) Nitrate removal from a drinking water supply with large free-surface constructed wetlands prior to groundwater recharge. Ecological Engineering 14(1-2), 33-47.

Richards R. P., Baker D. B., Creamer N. L., Kramer J. W., Ewing D. E., Merryfield B. J., and Wallrabenstein L. K. (1996a) Well water quality, well vulnerability, and agricultural contamination in the Midwestern United States. Journal of Environmental Quality 25(3), 389-402.

Richards R. P., Baker D. B., Creamer N. L., Kramer J. W., Ewing D. E., Merryfield B. J., and Wallrabenstein L. K. (1996b) Well water quality, well vulnerability, and agricultural contamination in the Midwestern United States (Vol 25, Pg 389, 1996). Journal of Environmental Quality 25(4), 930-930.

Robertson W. D., Cherry J. A., and Sudicky E. A. (1991) Ground-water contamination from 2 small septic systems on sand aquifers. Ground Water 29(1), 82-92.

SCVWD. (1994) Llagas Groundwater Basin Nitrate Study: Nitrate Source Area Identification, Contract 1-053-250-0, Santa Clara Valley Water District (prepared by T. L. Anderson, K. K. Yee, and H. A. Ude).

SCVWD. (1996) Llagas Groundwater Basin Nitrate Study: Public Draft Final Report, Contract 1-053-250-0, Santa Clara Valley Water District (prepared by M. J. Duffy, H. A. Ude, T. L. Anderson, M. A. Silva, and K. Parton).

Seiler R. L., Zaugg S. D., Thomas J. M., and Howcroft D. L. (1999) Caffeine and pharmaceuticals as indicators of waste water contamination in wells. Ground Water 37(3), 405-410.

Squillace P. J., Scott J. C., Moran M. J., Nolan B. T., and Kolpin D. W. (2002) VOCs, pesticides, nitrate, and their mixtures in groundwater used for drinking water in the United States. Environmental Science \& Technology 36(9), 1923-1930.

Standley L. J., Kaplan L. A., and Smith D. (2000) Molecular tracers of organic matter sources to surface water resources. Environmental Science \& Technology 34(15), 3124-3130.

SWRCB.(2002) Geotracker, (http://www.swrcb.ca.gov/cwphome/ust/docs/geotracker/).

Tesoriero A. J. and Voss F. D. (1997) Predicting the probability of elevated nitrate concentrations in the Puget Sound Basin: Implications for aquifer susceptibility and vulnerability. Ground Water 35(6), 1029-1039. 
Tiedje J. M. (1988) Ecology of denitrification and dissimilatory nitrate reduction to ammonium. In Biology of Anaerobic Microorganisms (ed. A. J. B. Zehnder), pp. 179-. John Wiley \& Sons.

U.S. EPA. (1990a) Drinking water criteria document on nitrate/nitrite, PB-91-142836, Criteria and Standards Division, Office of Drinking Water, U.S. Environmental Protection Agency.

U.S. EPA. (1990b) Estimated national occurrence and exposure to nitrate/nitrite in public drinking water supply wells, EPA contract no. 68-03-3514, U.S. Environmental Protection Agency.

U.S. EPA. (1991) National primary drinking water regulations: Final rule. U.S. Environmental Protection Agency, 40 CFR Parts 141, 142, and 143. Federal Register 56(20), 3526-97.

USDA. (1997) Water Quality and Agriculture: Status, Conditions and Trends, United States Department of Agriculture Natural Resources Conservation Service.

Ward M. H., Mark S. D., Cantor K. P., Weisenburger D. D., Correavillasenor A., and Zahm S. H. (1996) Drinking water nitrate and the risk of non-Hodgkins lymphoma. Epidemiology 7(5), 465-471.

Weyer P. J., Cerhan J. R., Kross B. C., Hallberg G. R., Kantamneni J., Breuer G., Jones M. P., Zheng W., and Lynch C. F. (2001) Municipal drinking water nitrate level and cancer risk in older women: The Iowa Women's Health Study. Epidemiology 12(3), 327-338.

Wilson J. P., Inskeep W. P., Wraith J. M., and Snyder R. D. (1996) GIS-based solute transport modeling applications - Scale effects of soil and climate data input. Journal of Environmental Quality 25(3), 445-453.

Zhao T., Doyle M. P., Shere J., and Garber L. (1995) Prevalence of enterohemorrhagic Escherichia coli O157-H7 in a survey of dairy herds. Applied and Environmental Microbiology 61(4), 1290-1293.

Zone 7 Water Agency. (2002) Groundwater nitrate sources in the Buena Vista area, Zone 7 Water Agency (prepared by Raines, Melton \& Carella, Inc.). 